
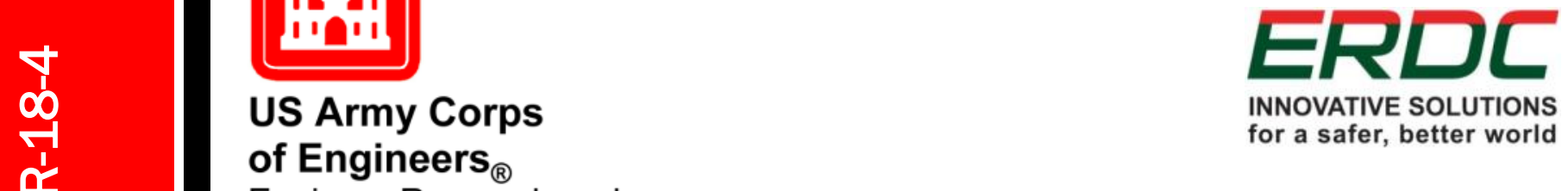
INNOVATIVE SOLUTIONS of Engineers ${ }_{\circledast}$ for a safer, better world Engineer Research and Development Center

Engineering for Polar Operations, Logistics, and Research (EPOLAR)

\title{
Using Ground-Penetrating Radar to Delineate Regions of Massive Ice at McMurdo Station, Antarctica
}

Samantha Sinclair, Seth Campbell, Steven Arcone,

March 2018 and Rosa Affleck

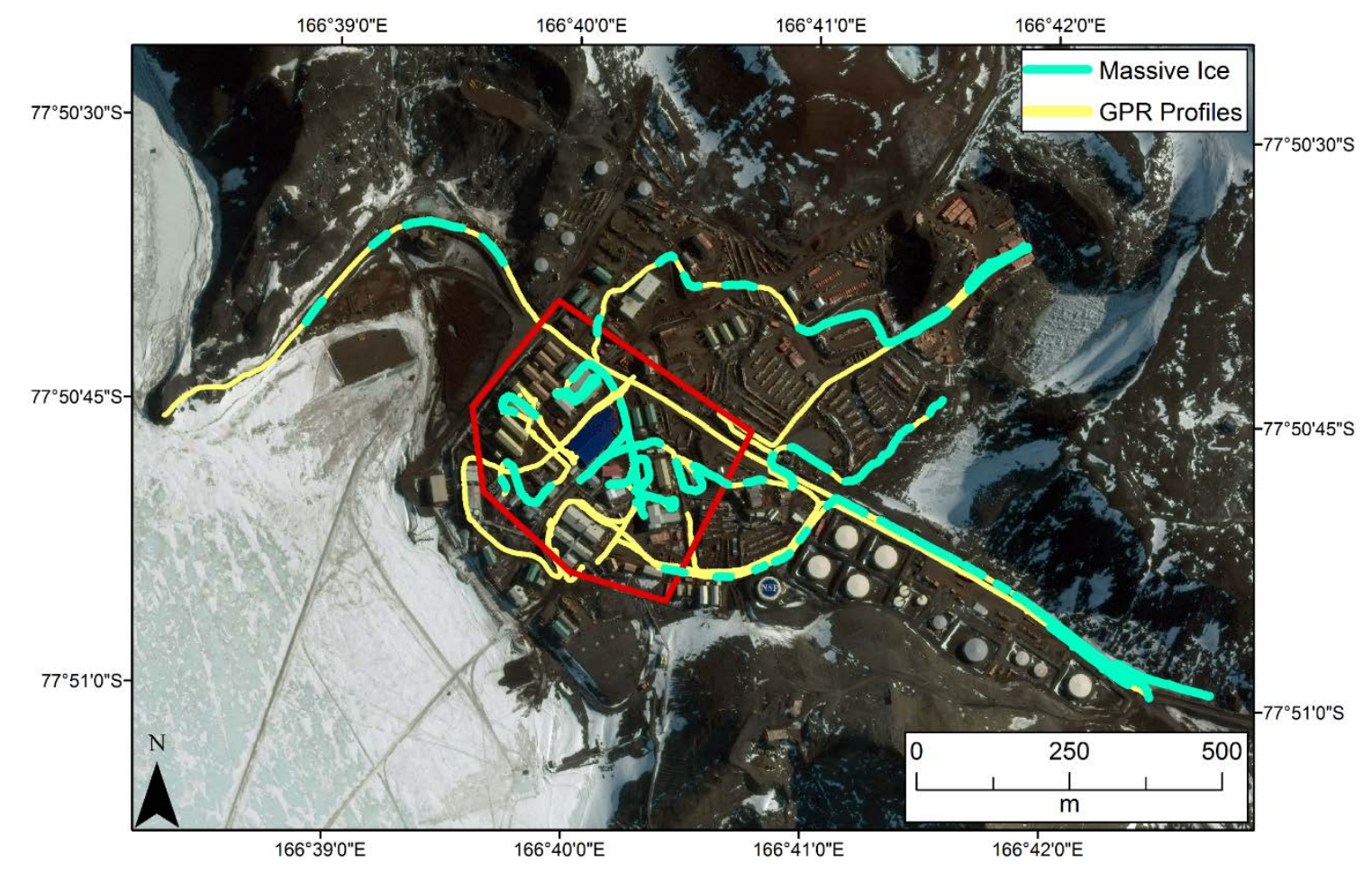


The U.S. Army Engineer Research and Development Center (ERDC) solves the nation's toughest engineering and environmental challenges. ERDC develops innovative solutions in civil and military engineering, geospatial sciences, water resources, and environmental sciences for the Army, the Department of Defense, civilian agencies, and our nation's public good. Find out more at www.erdc.usace.army.mil.

To search for other technical reports published by ERDC, visit the ERDC online library at http://acwc.sdp.sirsi.net/client/default. 


\section{Using Ground-Penetrating Radar to Delineate Regions of Massive Ice at McMurdo Station, Antarctica}

Samantha Sinclair, Seth Campbell, Steven Arcone, and Rosa Affleck

U.S. Army Engineer Research and Development Center (ERDC)

Cold Regions Research and Engineering Laboratory (CRREL)

72 Lyme Road

Hanover, NH 03755-1290

Final Report

Approved for public release; distribution is unlimited.

Prepared for National Science Foundation, Office of Polar Programs

2415 Eisenhower Avenue

Alexandria, VA 22314

Under Engineering for Polar Operations, Logistics, and Research (EPOLAR)

EP-ANT-17-67, "GPR Survey, Analysis, and Interpretation of McMurdo Station" 


\section{Abstract}

In November through December 2015, ground-penetrating-radar (GPR) data were collected at McMurdo Station, Antarctica, to better understand the near-surface geology, to find and delineate regions of excess or massive ice, and to inform future construction efforts. Of the $55 \mathrm{~km}$ of data collected, approximately $40 \%$ were analyzed and described in previous studies. In this study, we processed and analyzed the remaining data located within proposed areas for future construction. Both 400 and $200 \mathrm{MHz}$ antennas were used for data collection, with depth penetrations reaching 5 and $10 \mathrm{~m}$ for each antenna, respectively. Near-surface features detected include massive or excess ice, bedrock, and buried utilities. Ground-truth data, including soil pits and borehole logs, corroborate our interpretations. A considerable amount of near-surface excess ice likely has anthropogenic origins from runoff refreezing in shaded areas. Our results show that the subsurface of McMurdo is characterized by a substantial amount of frozen ground that will require navigation in both the planning and construction efforts associated with rebuilding McMurdo Station.

DISCLAIMER: The contents of this report are not to be used for advertising, publication, or promotional purposes. Citation of trade names does not constitute an official endorsement or approval of the use of such commercial products. All product names and trademarks cited are the property of their respective owners. The findings of this report are not to be construed as an official Department of the Army position unless so designated by other authorized documents. 


\section{Contents}

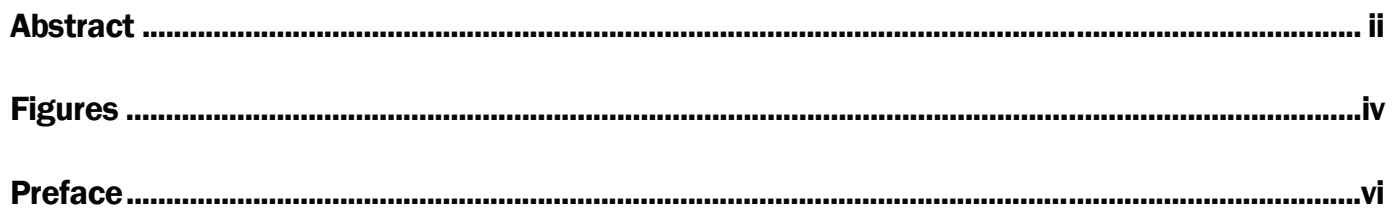

Acronyms and Abbreviations ..........................................................................................................vii

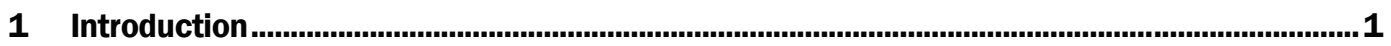

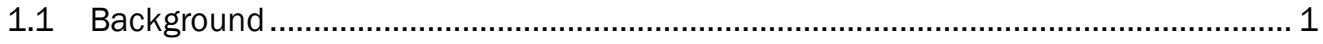

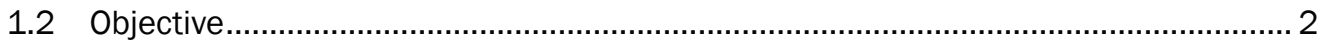

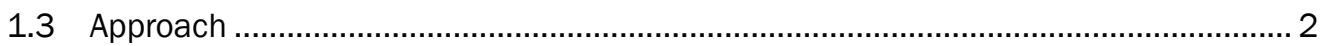

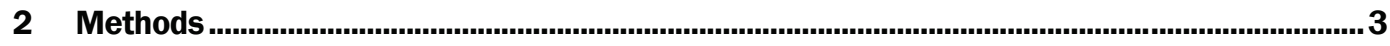

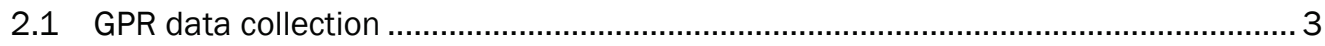

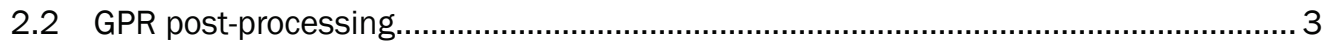

2.3 Interpretation methods and assumptions .................................................... 4

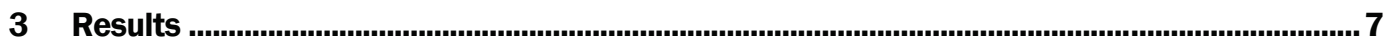

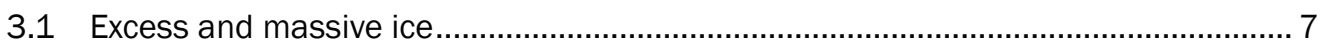

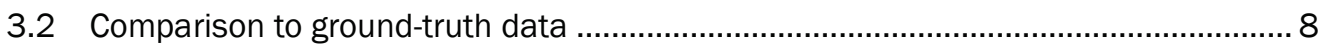

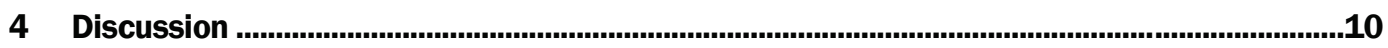

5 Conclusions and Recommendations .................................................................................12

References ..............................................................................................................................................13

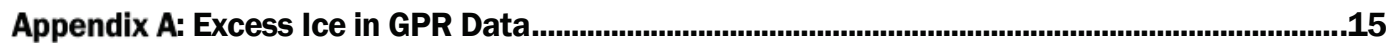

Report Documentation Page 


\section{Figures}

1 A map of Hut Point Peninsula on Ross Island, Antarctica....................................................... 1

2 A map of all GPR profiles collected at McMurdo Station in 2015 ...................................... 4

3 A map of all the regions of suspected massive ice at McMurdo Station that were interpreted from the GPR profiles .....................................................................................

4 Two GPR profiles that display buried massive ice.............................................................. 8

5 A map of the ground-truth data in the AOI compared to GPR interpretations ....................... 9

6 A GPR profile that displays typical roadway stratified fill.....................................................11

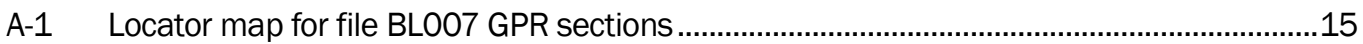

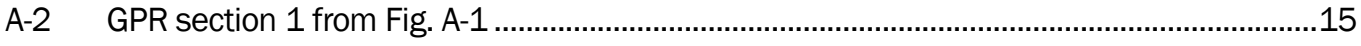

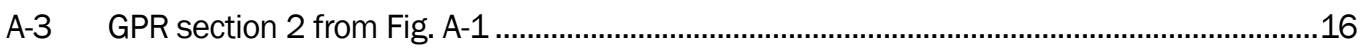

A-4 GPR section 3 from Fig. A-1 …………………........................................................16

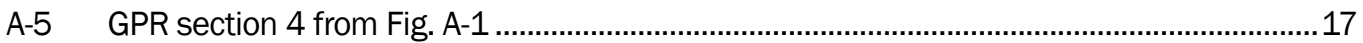

A-6 Locator map for file BL008 GPR sections...................................................................

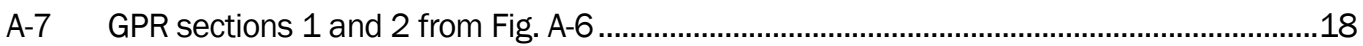

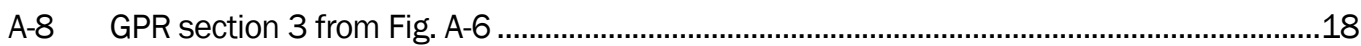

A-9 Locator map for file BL010 GPR section .......................................................................19

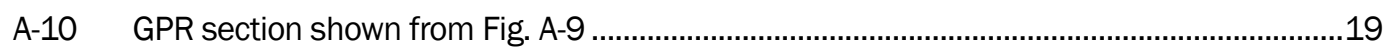

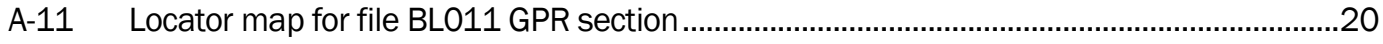

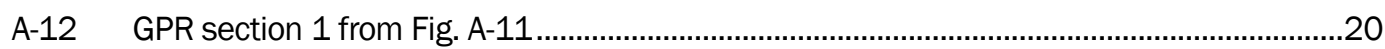

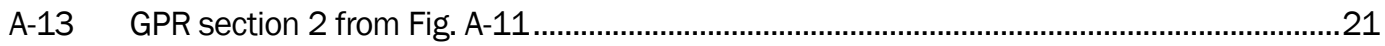

A-14 Locator map for file BL012 GPR sections ........................................................................21

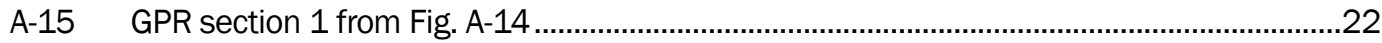

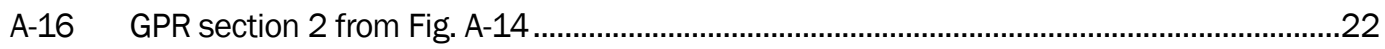

A-17 GPR sections 3 and 4 from Fig. A-14 ..........................................................................23

A-18 GPR section 5 from Fig. A-14 ........................................................................................23

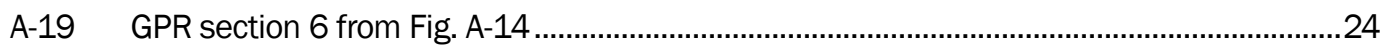

A-20 Locator map for file BL015 GPR sections .............................................................................2

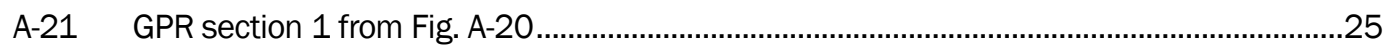

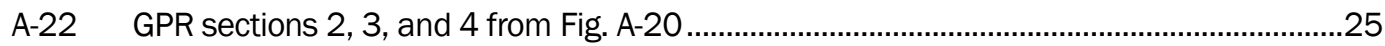

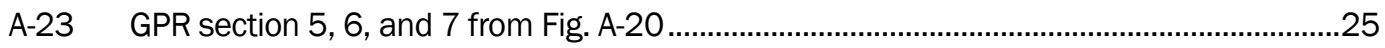

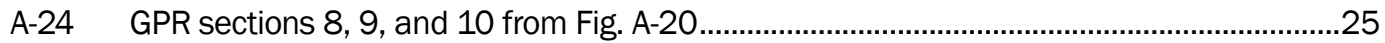

A-25 Locator map for file BL016 GPR sections ..........................................................................26

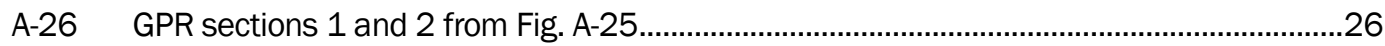

A-27 Locator map for file BL017 GPR sections ………............................................................2

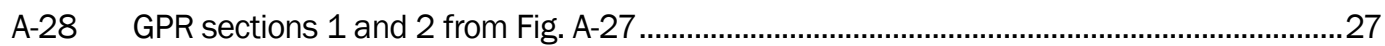

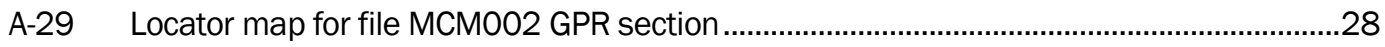

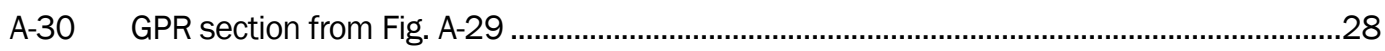

A-31 Locator map for file MCM004 GPR section ...........................................................................29 
A-32 GPR section 1 from Fig. A-31 ...........................................................................................29

A-33 GPR sections 2, 3, 4, and 5 from Fig. A-31.......................................................................29

A-34 Locator map for file P002 GPR sections ............................................................................30

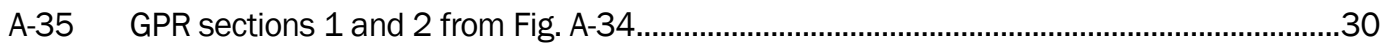

A-36 Locator map for file P003 GPR sections .............................................................................31

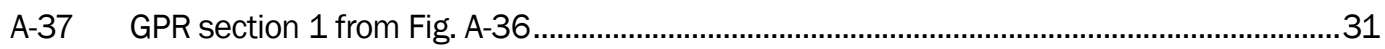

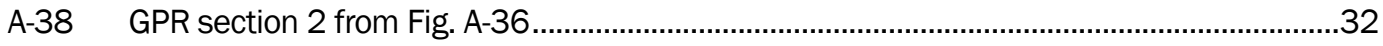

A-39 GPR sections 3, 4, and 5 from Fig. A-36 ..........................................................................32

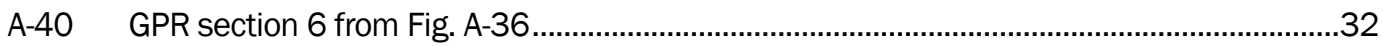




\section{Preface}

This study was conducted for the National Science Foundation (NSF) under Engineering for Polar Operations, Logistics, and Research (EPOLAR) EP-ANT-17-67, "GPR Survey, Analysis, and Interpretation of McMurdo Station." The technical monitor was Ms. Margaret Knuth, NSF Office of Polar Programs, Antarctic Infrastructure and Logistics.

This work was performed by the Terrestrial and Cryospheric Sciences Branch (CEERD-RRG), the Engineering Resources Branch (CEERD-RZE), the Signature Physics Branch (CEERD-RRD), and the Force Projection and Sustainment Branch (CEERD-RRH) of the Research and Engineering Division (CEERD-RR), U.S. Army Engineer Research and Development Center, Cold Regions Research and Engineering Laboratory (ERDCCRREL). At the time of publication, Dr. John Weatherly was Chief, CEERD-RRG; Mr. Jared Oren was Chief, CEERD-RZE; Dr. Andrew Niccolai was Chief, CEERD-RRD; Ms. Erin Bodie was Chief, CEERD-RRH; Mr. J. D. Horne was Chief, CEERD-RR; and Ms. Janet Hardy was the program manager for EPOLAR. The Deputy Director of ERDC-CRREL was Dr. Lance D. Hansen, and the Director was Dr. Joseph L. Corriveau.

We appreciate the Polar Geospatial Center for providing GIS (geographic information system) mapping support and UNAVCO for providing GPS (Global Positioning System) support.

COL Bryan S. Green was Commander of ERDC, and Dr. David W. Pittman was the Director. 


\section{Acronyms and Abbreviations}

$\begin{array}{ll}\text { AIMS } & \text { Antarctic Infrastructure Modernization in Support of Science } \\ \text { AOI } & \text { Area of Interest } \\ \text { CRREL } & \text { Cold Regions Research and Engineering Laboratory } \\ \text { EPOLAR } & \text { Engineering for Polar Operations and Logistics } \\ \text { ERDC } & \text { Engineer Research and Development Center } \\ \text { FIR } & \text { Finite Impulse Response } \\ \text { GIS } & \text { Geographic Information System } \\ \text { GPR } & \text { Ground-Penetrating Radar } \\ \text { GPS } & \text { Global Positioning System } \\ \text { GSSI } & \text { Geophysical Survey Systems Incorporated } \\ \text { IIR } & \text { Infinite Impulse Response } \\ \text { NSF } & \text { National Science Foundation } \\ \text { RTK } & \text { Real-Time Kinematic } \\ \text { TWTT } & \text { Two-Way Travel Time } \\ \text { USAP } & \end{array}$





\section{Introduction}

\subsection{Background}

McMurdo Station was established in 1955-1956 on the southern tip of Hut Point Peninsula on Ross Island in Antarctica (Figure 1) (Klein et al. 2008a). Initially erected by the United States Navy, McMurdo was never intended to be a permanent station but rather to serve as a temporary base camp to support the construction of South Pole Station (NSF [National Science Foundation] 2015; Davis 2017). As a result, McMurdo was built quickly and with limited planning. Since then, however, the station has developed into a central facility for research and logistics operations for the U.S. Antarctic Program (USAP) (Klein et al. 2008a).

Figure 1. A map of Hut Point Peninsula on Ross Island, Antarctica. The location of McMurdo Station relative to the rest of the continent is shown by the red dot on the indicator map located in the top right. The red polygon represents the area of interest that NSF selected for this project.

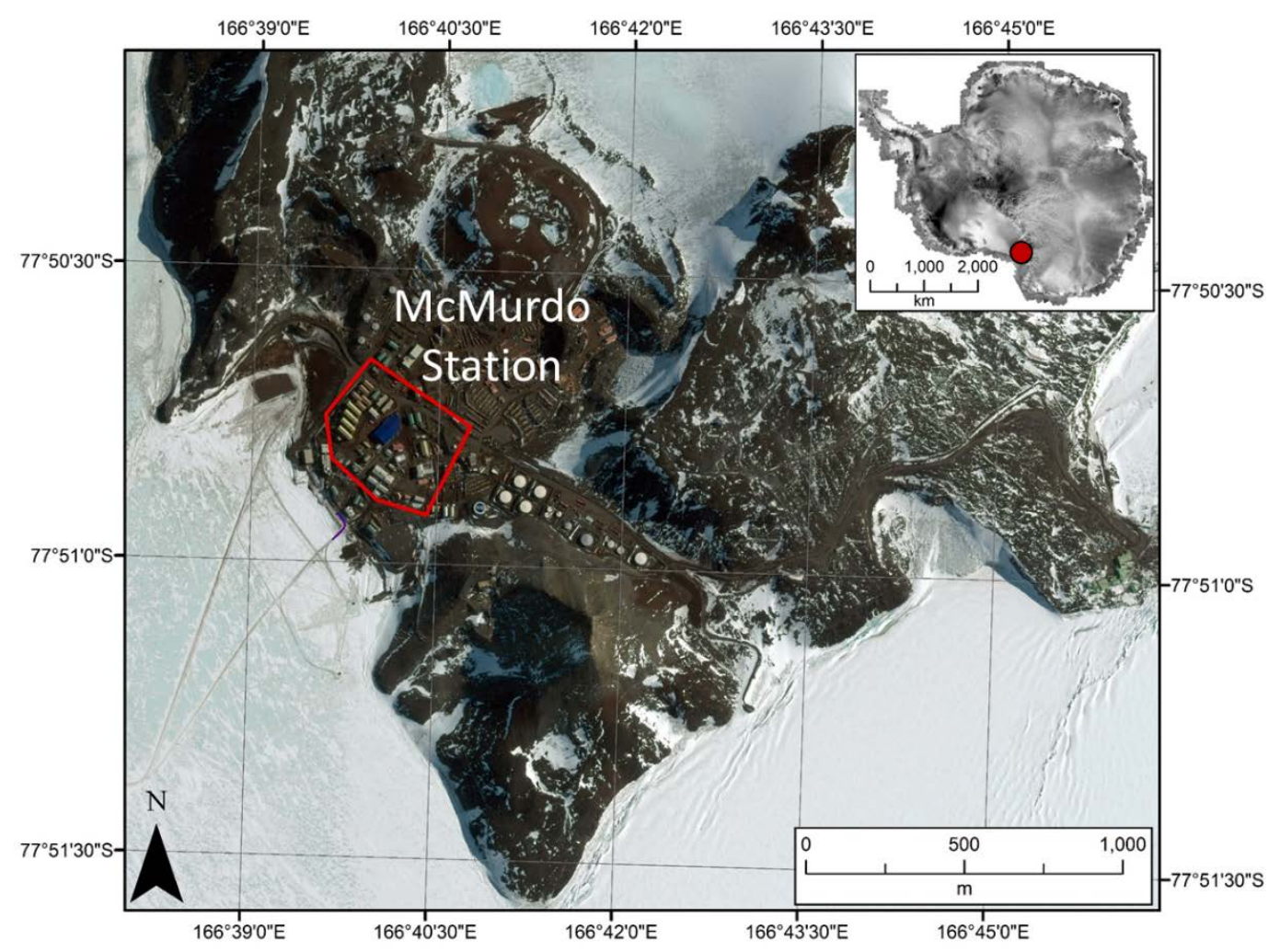

Over the last 60 years, the local area around McMurdo Station has been severely altered by anthropogenic activities. The construction of roads and 
buildings, surface scraping for fill materials, and contamination from spills have all impacted the surface and near subsurface (Klein et al. 2008b; Kennicutt et al. 2010). However, NSF has a long-term plan to rebuild McMurdo Station in support of the Antarctic Infrastructure Modernization in Support of Science (AIMS) initiative. USAP developed a master plan to modernize McMurdo into a more energy, environmentally, and operationally efficient station (NSF 2015). To support this substantial effort, Campbell et al. (2018) collected $55 \mathrm{~km}$ of ground-penetrating-radar (GPR) data in and around McMurdo Station to study both the natural and anthropogenically modified near-surface geology and to provide geotechnical guidance on construction planning, preparation, and design. Prior to our study, however, only approximately $40 \%$ of the dataset had been analyzed.

\subsection{Objective}

The goals of this study are to locate areas of excess or massive ice at McMurdo Station, to describe ice thickness and extent, and to provide geotechnical guidance for future construction efforts. To achieve these goals, our objective was to process and analyze the remainder of the GPR dataset that Campbell et al. (2018) collected in 2015. We define excess ice as "the volume of ice in the ground which exceeds the total pore volume that the ground would have under natural unfrozen conditions" (Harris et al. 1988, 45). We define massive ice as "a comprehensive term used to describe large masses of ground ice, including ice wedges, pingo ice, buried ice and large ice lenses" (Harris et al. 1988, 47). We primarily focused our efforts on analyzing data within an area-of-interest (AOI) bounding box provided by NSF that represents a highly probable region for future construction (see Figure 1).

\subsection{Approach}

We processed, analyzed, and interpreted GPR profiles and subsequently compared them to ground-truth data collected on or near each profile. Section 2 of this report provides the methodology used for data collection in the field and highlights assumptions made. It also lists all post-processing steps. Section 3 outlines our results and documents regions where we interpreted massive ice locations at McMurdo Station. Section 4 discusses our interpretations and correlations with ground-truth data and identifies areas of potential future research. The appendix provided contains all the GPR profiles and associated GIS (geographic information system) location maps where excess ice was detected. 


\section{Methods}

\subsection{GPR data collection}

Campbell et al. (2018) collected GPR data in November through December 2015 on and off roads and trails, covering both disturbed and undisturbed surfaces at McMurdo Station. Campbell et al. (2018) used a SIR-4000 GPR control unit coupled with model $5106200 \mathrm{MHz}$ and model 50400 $400 \mathrm{MHz}$ shielded antennas, each unit manufactured by Geophysical Survey Systems Incorporated (GSSI). The GPR was synchronized with a Trimble 5700 and Zephyr geodetic antenna that recorded Global Positioning System (GPS) locations at a frequency of $1 \mathrm{~Hz}$. GPR scans were recorded at 24 scans s$^{-1}$, and antennas were towed by hand on plastic sleds at about $0.5 \mathrm{~m} \mathrm{~s}^{-1}$, resulting in traces being recorded approximately every $2 \mathrm{~cm}$ in horizontal distance. GPR profiles were collected using a real-time kinematic (RTK) radio that transmitted at $418 \mathrm{MHz}$ for $200 \mathrm{MHz}$ profiles, resulting in 1-10 cm surface locational precision. The $400 \mathrm{MHz}$ profiles were collected with a handheld GPS unit because the RTK radio link interfered with the GPR signal, resulting in only 1 and $3 \mathrm{~m}$ locational accuracies with that antenna. Scans were recorded for 150-250 ns TWTT (two-way travel time) with 1024 samples per scan, resulting in about four samples per nanosecond, or 50-60 samples per meter recorded vertically. This vertical sample resolution is more than sufficient to maintain a smooth waveform given the frequencies used. High- and low-pass IIR (infinite impulse response) between $100-800 \mathrm{MHz}$ filtering and range gain were applied during data collection.

\subsection{GPR post-processing}

We post-processed GPR profiles using GSSI RADAN Version 7.0 proprietary software. All the profiles processed and analyzed in this study were partially or fully located within the AOI and are shown in Figure 2. Postprocessing included time-zero correction, integration of GPS data into the files, distance normalization, FIR (finite impulse response) filtering, horizontal background filtering to remove antenna ringing (noise generated from at- or near-surface interferences) and the direct wave (the signal between the transmitter and receiver) within the data, and stacking to improve signal-to-noise ratios and visualization of horizontal reflectors. We used RADAN to interpolate GPS locations between the duration of each GPS measurement. 
Figure 2. A map of all GPR profiles collected at McMurdo Station in 2015 (yellow lines). The red polygon outlines the $\mathrm{AOI}$ for this project. The blue circles represent the location of the boreholes drilled in 2015 to 2017 (Fenwick and Winkler 2016; Fenwick et al. 2017), and the green squares depict the location of the soil pits excavated in 2015 (Affleck at el. 2017).

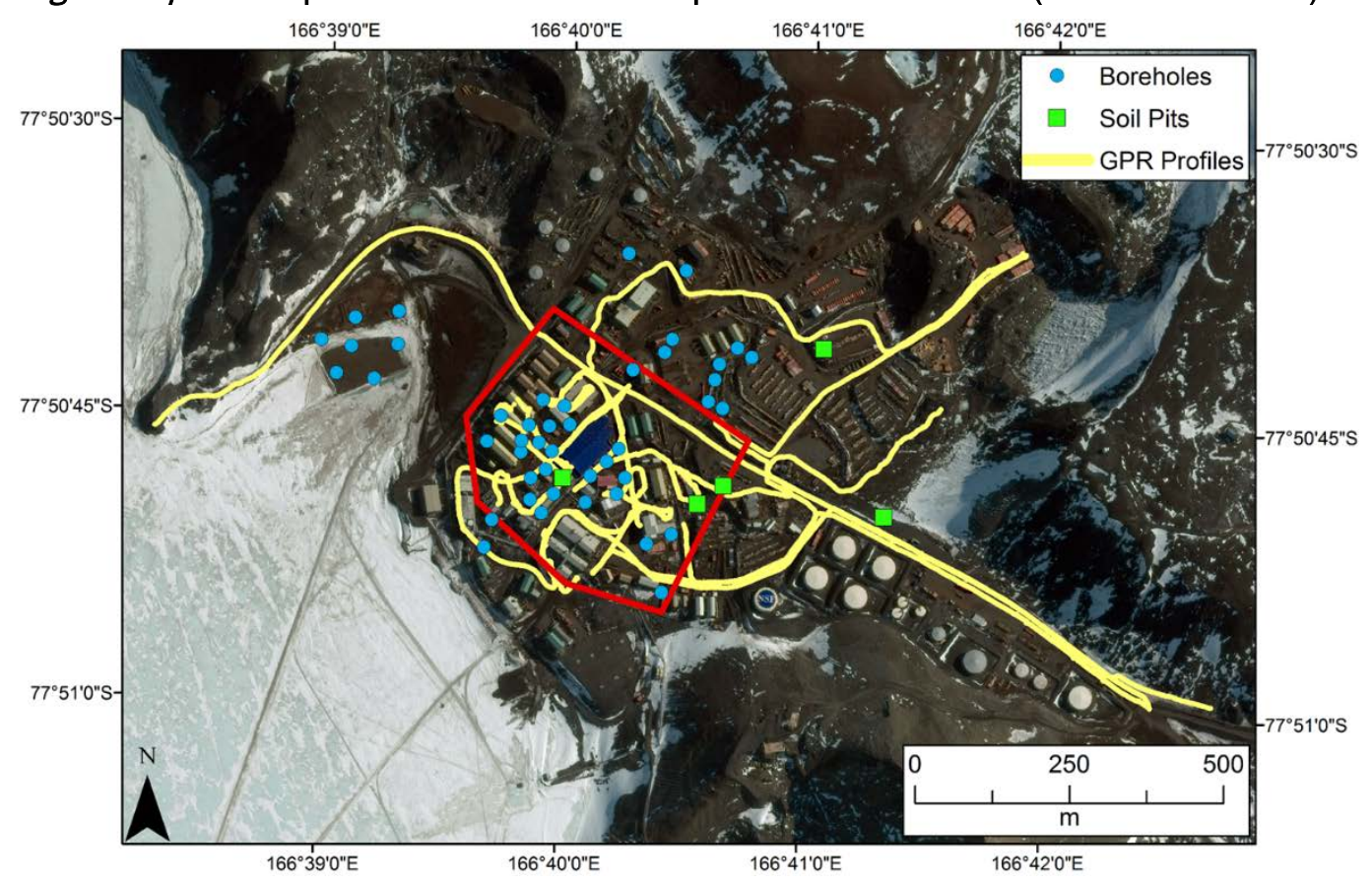

\subsection{Interpretation methods and assumptions}

Interpretation of geophysical data and depth calibration was performed by comparing depth and stratigraphy information from our dataset to that from borehole logs (Fenwick and Winkler 2016; Fenwick et al. 2017) and soil pits (Affleck et al. 2017). The cores and pits were generally located 1-2 $\mathrm{m}$ from GPR profiles, providing reasonable accuracy of structure and stratigraphic thicknesses. We assume some uncertainty in depth calculations because the datasets were not collected simultaneously, lateral differences exist in unit thicknesses, and there is some ambiguity in pit and core locations relative to GPR profiles.

Where pit and core observations were unavailable, depth calibration was performed via variable velocity migration of GPR profiles, a technique used to define velocities in regions where the subsurface composition changes with depth. In these regions, we also applied a variety of standard assumptions to complete interpretations based on physical radar responses. We used typical relative permittivity $(\dot{\varepsilon})$ values for (typically icesaturated) permafrost (5.3), basalt (6-12), fill (6-12), and ice (3) to determine expected geophysical responses at interfaces between geological structures (Elshafie and Heggy 2012, 2013; Rust et al. 1999). Waveform 
polarity of the first three half cycles results from an interface between two materials that have $\dot{\varepsilon}$ contrasts. When a positive $(+-+)$ triplet occurs, it suggests that the deeper layer has a higher $\dot{\varepsilon}$; and when a negative $(-+-)$ triplet occurs, it suggests that the deeper layer has a lower $\dot{\varepsilon}$, each relative to the shallower layer. For example, ice buried below frozen till would display a negative triplet response because of the transition from higher to lower $\dot{\varepsilon}$. Recognizing that there is some overlap of $\dot{\varepsilon}$ values between different geological materials, we incorporated migration and diffraction analyses of GPR profiles to confirm or provide ranges for $\dot{\varepsilon}$ and therefore associated wave velocities and depths of features imaged using GPR. Surface diffractions and migrations estimated values of $\dot{\varepsilon}$ between 6 and 12, which is consistent with erosion-resistant basalts (Elshafie and Heggy 2012, 2013). In the following equations, we used these assumptions and calculations to calculate the depth of features in areas where GPR profiles were collected but where ground-truth information was not available:

$$
\begin{gathered}
V=\frac{c}{\sqrt{\varepsilon}} \\
d=\frac{\left(T W T T^{*} V\right)}{2}
\end{gathered}
$$

where

$$
\begin{aligned}
V & =\text { velocity }\left(\mathrm{m} \mathrm{ns}^{-1}\right) \\
c & =\text { the speed of light } \\
d & =\text { depth }(\mathrm{m}), \text { and } \\
T W T T & =\text { two-way travel time (ns). }
\end{aligned}
$$

Following the ground-truth and geophysical assumptions above, we also applied geomorphological and geological knowledge of near-surface structures to our GPR interpretations. For example, we assumed that horizontal and relatively continuous horizons were anthropogenically altered and layered fill or stratified fine-grain materials deposited from summer water runoff. In contrast, we interpreted regions that exhibited unstratified or discontinuous horizons and numerous diffractions or hyperbolas as buried till, dumped and unsorted debris, or heavily fractured and weathered bedrock. These assumptions were based on the expected physical responses from GPR in till and bedrock environments (e.g., Arcone et al. 2014). Because of the heavily fractured and variable or rough, exposed bedrock surfaces surrounding McMurdo, we developed a strategy to interpret bedrock 
horizons under stratified or unstratified material through two primary assumptions. First, we assumed that consistent terminations of stratified till against an unconformity were likely a bedrock contact. Second, the interface between fill and bedrock often consisted of discrete but multiple hyperbolas that created a relatively continuous horizon, suggesting a rough but definitive surface between the overburden matrix relative to material below. Multiple ground-truth points where bedrock outcrops occur at or near the surface in McMurdo support our interpretation that these geophysical signatures likely represent a fill-bedrock contact. Finally, GPR profiles over surface-exposed bedrock revealed high attenuation rates, suggesting that below a fill-bedrock horizon, signal penetration would significantly diminish. Therefore, in some cases, we used a combination of the horizon triplet response, diffractions, and high attenuation below the horizon as grounds for bedrock interpretations. The interpretation scheme above results in a classification that distinguishes between stratified fill (such as road fill), unstratified material (such as naturally deposited till or heavily fractured bedrock), structurally sound bedrock, and regions of either massive ice or frozen ground. 


\section{Results}

\subsection{Excess and massive ice}

Of the 15 radar profiles examined in this study, 12 contained areas of excess or massive ice, 8 of which fell within the AOI (Figure 3; Appendix A). Excess ice was distinguished by a high concentration of hyperbolic spatial signatures in the radar profiles and was found both near the surface and at greater depths (Figure 4). The majority of excess ice within the AOI was located at a depth between 0 and $5 \mathrm{~m}$, though in some areas, it was found as deep as 7.5 m. In several instances where two different GPR profiles intersected, the overlapping sections of each profile concurred with one another (i.e., we identified excess ice or a lack thereof in both profiles), which provides a level of confidence in our interpretations. In two situations where intersecting profiles did not agree, radar signal attenuation or noise in one of the profiles made interpretation along that segment impossible.

Figure 3. A map of all the regions of suspected massive ice at McMurdo Station that were interpreted from the GPR profiles.

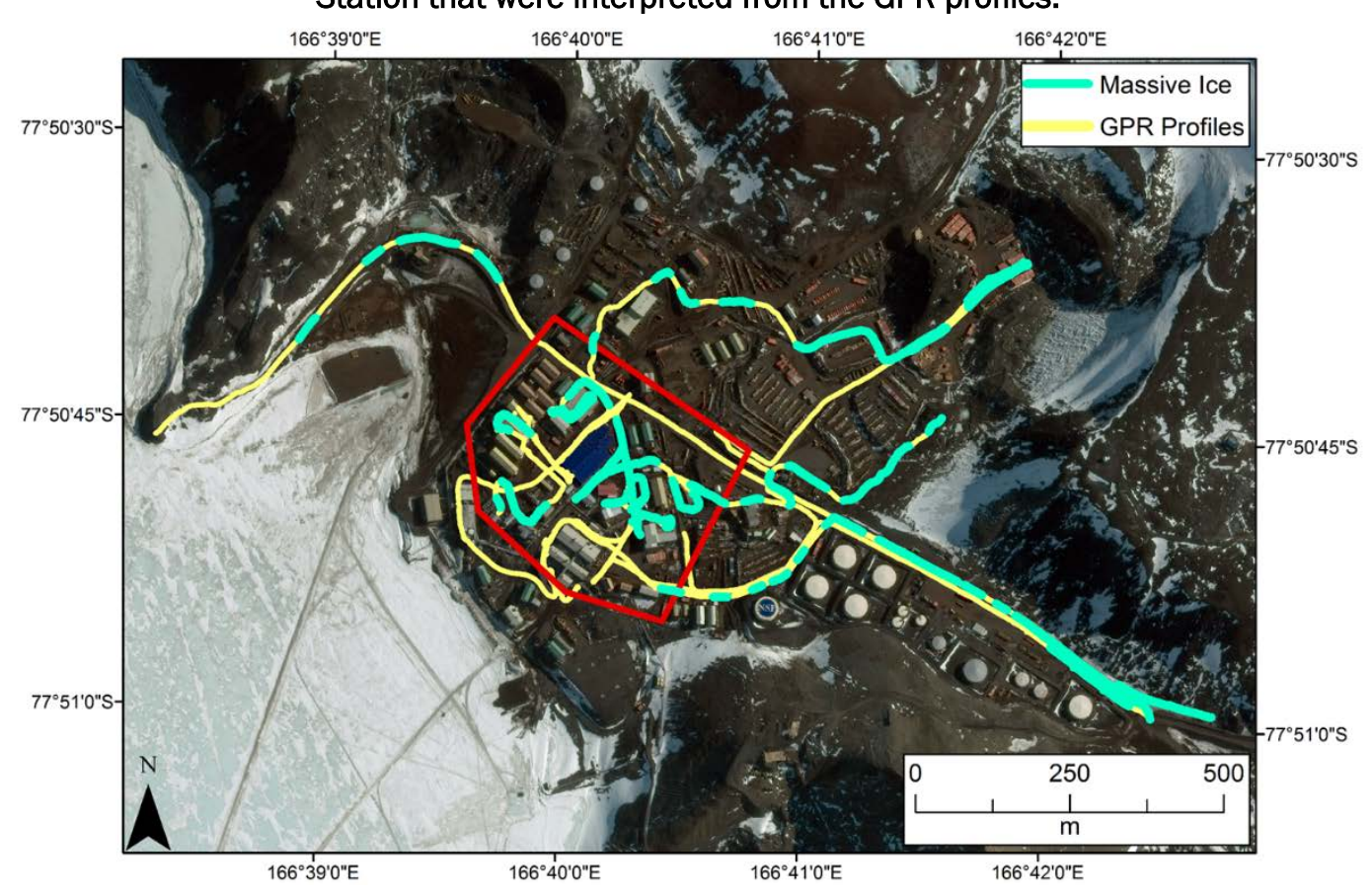


Figure 4. Two GPR profiles, collected with a $200 \mathrm{MHz}$ antenna, that display buried massive ice. Concentrations of near-surface (0-5 m, top panel) and deep (5-10 m, bottom panel) buried massive ice can be viewed within the two red ovals. Indicator maps are shown in the bottom right of each profile. The highlighted section outlines the portion of the profile displayed here, and the arrows indicate the direction in which the profiles were collected.

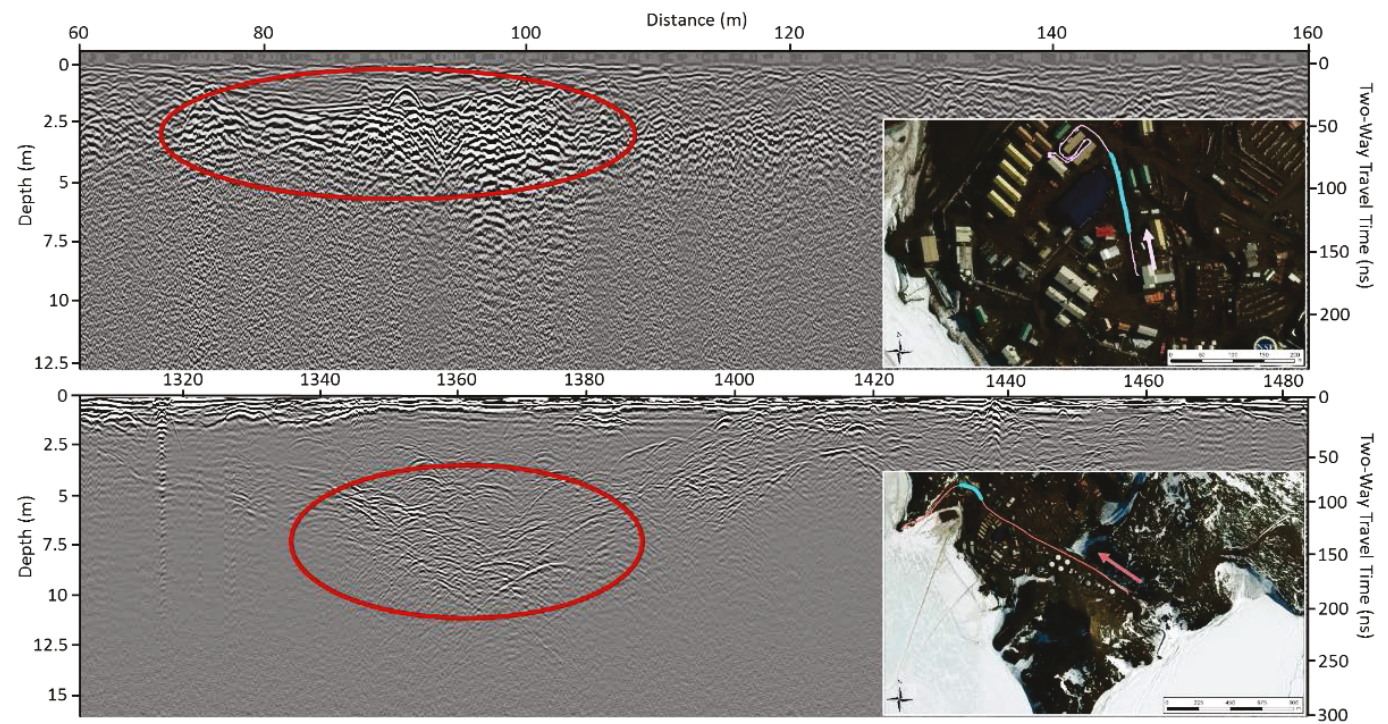

\subsection{Comparison to ground-truth data}

In 2015-2017, Golder Associates drilled 74 boreholes in and around McMurdo Station, over half of which are located within the AOI associated with this project (Fenwick and Winkler 2016; Fenwick et al. 2017). Golder Associates classified ice found within the cores into three categories: ice greater than $25 \mathrm{~mm}$ thick (called ice-rich here), ice less than $25 \mathrm{~mm}$ thick (called ice-present here), and ice not visible with the naked eye (called icepoor here) (Fenwick et al. 2017). We examined the borehole logs relevant to this study and sorted them based on the frozen soil classification scheme used by Golder Associates. Each borehole was color coded based on whether the majority ( $\geq 50 \%$ ) of the core was ice-rich (dark blue), icepresent (teal), or ice-poor (yellow) (see Figure 5). Of all cores, $89 \%$ were classified as either ice-rich or ice-present, and most ice-poor cores also contained ice.

Cores drilled either directly on top of or within 1-2 m of the GPR profiles were used as ground-truth data to confirm the presence or absence of excess ice (for an example of a borehole log and GPR profile comparison, see Campbell et al. 2018). In general, there is a strong agreement between our GPR interpretations and the borehole records, with four notable exceptions. In three of these instances, cores classified as ice-present were 
marked at or within $2 \mathrm{~m}$ of GPR profiles where excess ice was not delineated (cores 50, 34, and 13; see Figure 5). In one instance, a core classified as ice-rich was located on a GPR profile where excess ice was not detected (core 25; see Figure 5). Discrepancies between GPR interpretations and cores located more than $2 \mathrm{~m}$ apart were not addressed because subsurface information gained from GPR surveys cannot be extrapolated laterally more than a couple meters.

Figure 5. A map of the ground-truth data in the AOI compared to GPR interpretations. Cores were grouped based on the frozen soil classification scheme used by Golder Associates (Fenwick et al. 2017). Dark blue, teal, and yellow circles depict cores that contain $\geq 50 \%$ ice-rich, ice-present, or ice-poor sediments, respectively. The three soil pits in this area are labeled. Note that core 13 is directly underneath pit 5 . Cores $50,34,25$, and 13 are labeled as these are the only ground-truth records in the region that did not agree with GPR interpretations.

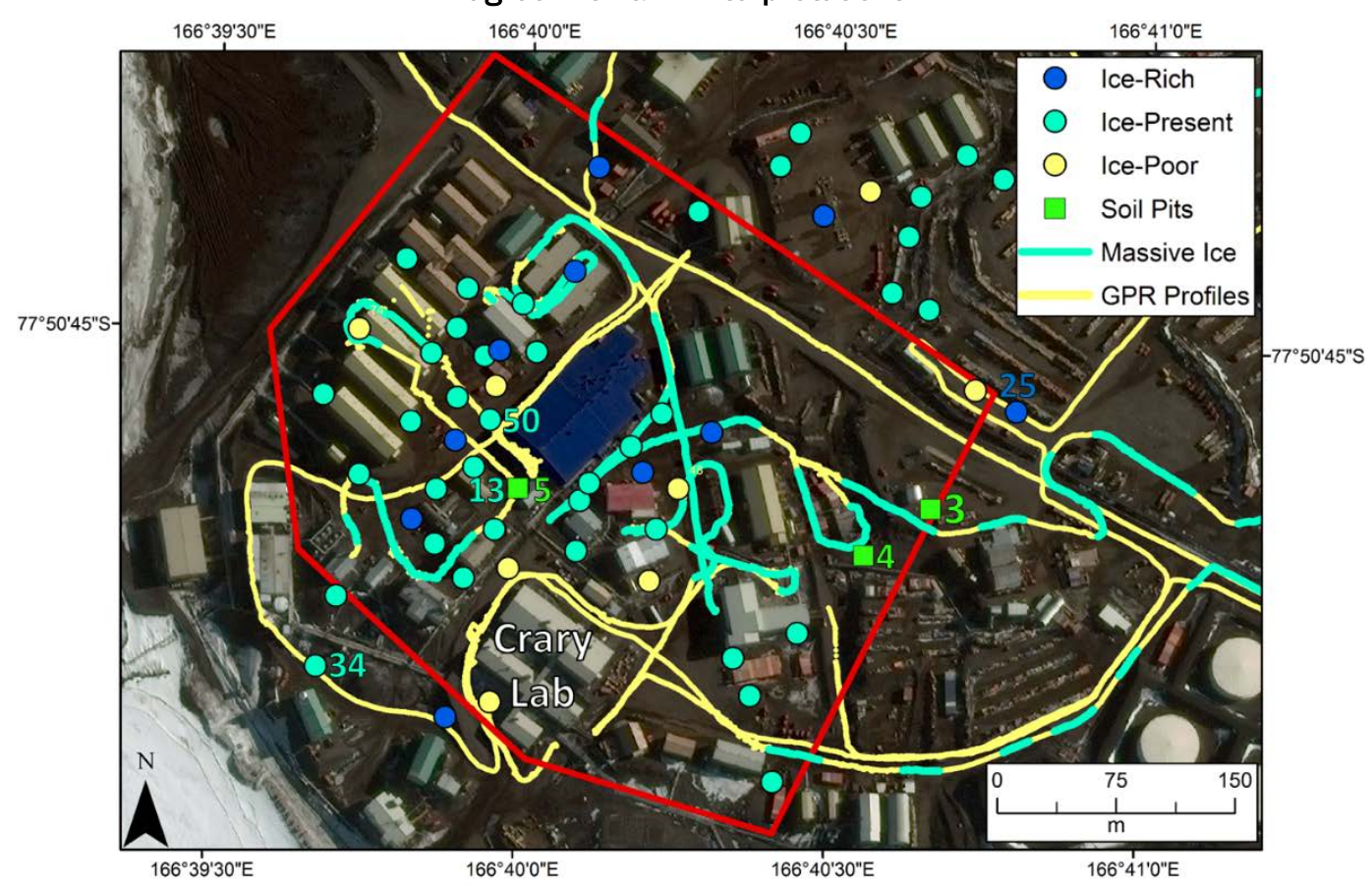

Affleck et al. (2017) dug and analyzed five soil pits, three of which are located within the AOI (see Figure 5). Pit 3 was dug $1.7 \mathrm{~m}$ deep and contained man-made fill, contaminants, and permafrost. Pits 4 and 5 were both dug to $3.05 \mathrm{~m}$ and contained massive ice and ice lenses, respectively (Affleck et al. 2017). Pit 5 is located in the same place as core 13, and both record a substantial amount of excess ice. However, these two records were extracted along a portion of a GPR profile where massive ice was not delineated (see Figure 5). 


\section{Discussion}

The dataset reviewed in this report provides one of the most comprehensive records of the subsurface structure of McMurdo Station to date. Our findings indicate that the terrain at McMurdo is largely ice-rich, which is a significant hurdle that will need to be navigated during future construction activities, particularly as buried massive ice was detected in regions highlighted by NSF for future rebuilding. NSF should also consider estimates of excess-ice thickness provided in this report, as frozen ground extends to a minimum of $5 \mathrm{~m}$ below the surface (see Appendix A). While our results supplement previous drilling efforts, they also provide a substantially greater amount of coverage across McMurdo compared to the point measurements of cores and soil pits. For this reason, we believe GPR should be used to inform or compliment any future drilling projects.

The strong agreement between the GPR and ground-truth data largely corroborates our interpretations. The instances where discrepancies exist between the two datasets are a product of either (1) signal attenuation and noise or (2) man-made structures and anthropogenic ice. For example, records indicate that core 13 and soil pit 5 contain a substantial amount of ice, yet both are located along a portion of a GPR profile where massive ice was not delineated (see Figure 5). This profile showed subhorizontal, relatively continuous reflectors in the upper $2.5 \mathrm{~m}$ of the dataset in the region where core 13 and pit 5 are located (Figure 6). These reflections are typical of roadway stratified fill at McMurdo and suggest that the terrain has been anthropogenically altered (Campbell et al. 2018). While we did not observe or mark diffractions indicative of massive ice at this site, the stratified fill likely contains ice from summer melt that drained into the roadway and froze again in the winter or snow that was pushed and flattened into the roadway. This is also the case for core 50, which is labeled ice-present on a portion of a GPR profile that does not have delineated ice (yet stratified road fill was identified). In the case of cores 25 and 34, signal attenuation made interpretation along that portion of the profile impossible, which is why excess ice was not detected at those sites yet was found within the corresponding cores.

The interaction of GPR signals with water and ice represents two ends of the geophysical spectrum. That is, within most situations where the nearsurface geology is water-rich, the radar signal is significantly attenuated 
and noisy. In contrast, ice-rich near-surface geology minimizes radar signal attenuation, allowing it to penetrate to greater depths while concurrently diffracting off any subsurface anomalies, such as buried boulders or bedrock fractures. This geophysical response is the primary reason why ice-rich regions in the form of either excess or massive ice display numerous diffractions, greater penetration depths, and more structural detail than regions that are ice-poor. This geophysical response is also one of the primary underlying principles we use for subsurface interpretations. In general, we interpret regions that display greater depths of radar signal penetration and greater subsurface structural detail to be ice-rich.

Figure 6. A GPR profile, collected with a $200 \mathrm{MHz}$ antenna, that displays typical roadway stratified fill. Relatively continuous horizontal reflections within the top $2.5 \mathrm{~m}$ (highlighted by the black arrows) are a result of a pathway continuously flattened by construction or vehicles. This section likely contains anthropogenic ice that melts, pools, and refreezes seasonally. An indicator map is shown in the bottom right. The highlighted section outlines the portion of the profile displayed here, and the yellow arrow indicates the direction in which the profile was collected.

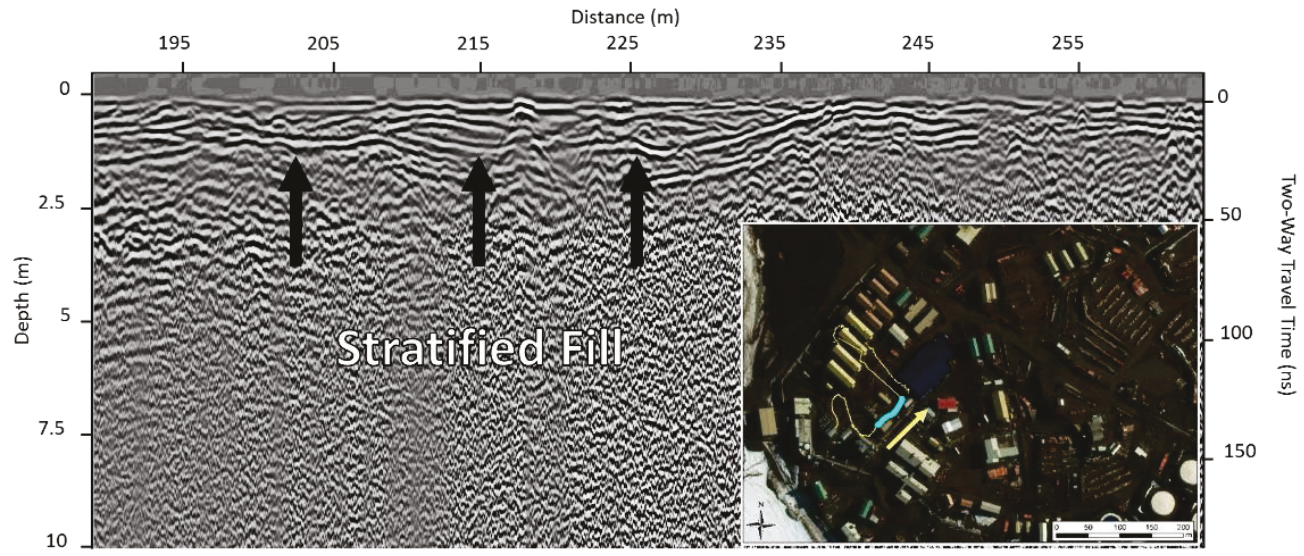

A significant amount of ice at McMurdo Station has likely been generated anthropogenically. As McMurdo is surrounded by hillslope and largely consists of man-made platforms and roads, it is likely that melt consistently runs off the hills in the summer months and percolates into the subsurface, eventually refreezing on an annual basis (Affleck et al. 2017). Campbell et al. (2018) documented an example of this process occurring at Crary Laboratory (see Figure 5) where shading underneath the building allowed for melt to refreeze and form buried excess ice. 


\section{Conclusions and Recommendations}

This study processed, analyzed, and interpreted over $30 \mathrm{~km}$ of GPR data collected in 2015 at McMurdo Station, Antarctica. Both 400 and $200 \mathrm{MHz}$ antennas were used for data collection, with depth penetrations reaching 5 and $10 \mathrm{~m}$ for each antenna, respectively. Near-surface features detected include buried utilities, bedrock, and massive or excess ice. Regions of excess ice were delineated and described in this study, and our results show that most ice is located between $\mathrm{o}$ and $5 \mathrm{~m}$ deep, but some is found as deep as $10 \mathrm{~m}$. We assume that regions where signal attenuation is low and distinct diffractions are visible are a signature of ice. Our data reveal that the subsurface terrain at McMurdo is highly ice-rich, which will need to be considered during future construction efforts.

Ground-truth soil pit and core information largely concur with our interpretations. Of over 50 ground-truth data-point measurements examined in this study that were within $2 \mathrm{~m}$ of our profiles, only four did not agree with our interpretations. In these four instances, signal attenuation or the presence of man-made structures caused the discrepancy. In other scenarios where GPR and ground-truth data did not agree, cores or soils pits were located too far from the profile to be used for one-to-one comparisons. We recommend that future drilling or other geotechnical efforts at McMurdo Station are supplemented with GPR data to provide a broader picture of the subsurface geology compared to point-measurement drilling results.

Based on our findings, we believe that a considerable amount of near-surface excess ice at McMurdo was created anthropogenically from runoff refreezing in shaded areas and the packing of snow into roads. Future studies should address the problem of artificial ice generation because this process could likely further inhibit construction activities. We recommend a future study at McMurdo that involves using high-resolution digital elevation data in conjunction with recent hydrogeology studies to analyze where ice deposits may form at the station. This future data could be used in tandem with the results from our study and other geotechnical information that is available (Fenwick and Winkler 2016; Affleck et al. 2017; Fenwick et al. 2017; Campbell et al. 2018) to better determine where excess ice-rich regions are located at McMurdo. Future studies should also collect more geotechnical information such as GPR in and around the dormitory buildings at McMurdo as limited subsurface information is currently available in this area. 


\section{References}

Affleck, R. T., S. Campbell, S. Sinclair, and B. Tischbein. 2017. Subsurface Assessment at McMurdo Station, Antarctica. ERDC/CRREL TR-17-4. Hanover, NH: U.S. Army Engineer Research and Development Center.

Arcone, S. A., S. Campbell, and W. T. Pfeffer. 2014. GPR Profiles of Glacial Till and Its Transition to Bedrock: Interpretation of Water Content, Depth and Signal Loss from Diffractions. Journal of Engineering and Environmental Geophysics 19 (4): 207-228.

Campbell, S., R. Affleck, and S. Sinclair. 2018. Ground-Penetrating Radar Studies of Permafrost, Periglacial, and Near-Surface Geology at McMurdo Station, Antarctica. Cold Regions Science and Technology 148:38-49.

Davis, G. A. 2017. A History of McMurdo Station through its Architecture. Polar Record 53 (2): $167-185$.

Elshafie, A., and E. Heggy. 2012. Dielectric Properties of Volcanic Material and Their Role for Assessing Rock. In Proceedings, 43rd Lunar and Planetary Sciences Conference, 19-23 March, Woodlands, TX, 43:43-44.

—. 2013. Dielectric and Hardness Measurements of Planetary Analog Rocks in Support of In-Situ Subsurface Sampling. Planetary and Space Science 86:150154 .

Fenwick, J., and D. Winkler. 2016. Geotechnical Assessment Report: McMurdo Station, Ross Island, Antarctica. Report Number 1535646_7407-002-R-Revo. Toronto, Canada: Golder Associates.

Fenwick, J., D. Winkler, and B. Neahusan. 2017. Geotechnical Assessment Report: McMurdo Station, Ross Island, Antarctica-Phase II. Report Number 1535646_7407-007-R-Revo. Toronto, Canada: Golder Associates.

Harris, S. A., H. M. French, J. A. Heginbottom, G. H. Johnston, D. C. Ladanyi, and R. O. van Everdingen. 1988. Glossary of Permafrost and Related Ground-Ice Terms. Technical Memorandum Number 142. Ottawa, Canada: Permafrost Subcommittee, Associate Committee on Geotechnical Research, National Research Council of Canada.

Kennicutt, M. C., II, A. Klein, P. Montagna, S. Sweet, T. Wade, T. Palmer, J. Sericano, and G. Denoux. 2010. Temporal and Spatial Patterns of Anthropogenic Disturbance at McMurdo Station, Antarctica. Environmental Research Letters 5 (3): 1-10.

Klein, A. G., M. C. Kennicutt, G. A. Wolff, S. T. Sweet, T. Bloxom, D. A. Gielstra, and M. Cleckley. 2008a. The Historical Development of McMurdo Station, Antarctica, an Environmental Perspective. Polar Geography 31 (3-4): 119-144.

Klein, A. G., M. C. Kennicutt, G. A. Wolff, S. T. Sweet D. A. Gielstra, and T. Bloxom. 2008b. Disruption of Sand-Wedge Polygons at McMurdo Station, Antarctica: An Indication of Physical Disturbance. In Proceeding of the 61st Eastern Snow Conference, 9-11 June, Portland, ME, 159-172. 
NSF (National Science Foundation). 2015. McMurdo Station Master Plan 2.1. Arlington, Virginia: National Science Foundation.

Rust, A. C., J. K. Russell, and R. J. Knight. 1999. Dielectric Constant as a Predictor of Porosity in Dry Volcanic Rocks. Journal of Volcanology and Geothermal Research 91 (1-2): 79-96. 


\section{Appendix A: Excess Ice in GPR Data}

The following figures (Figures A-1 to A-40) represent all GPR profiles collected across the McMurdo Station study region in November of 2015 that contained regions of excess or buried massive ice. A locator map is provided for each set of GPR figures.

Figure A-1. Locator map for file BL007 GPR sections (Figs. A-2 to A-5) with blue lines denoting areas that contain excess or massive ice and yellow lines representing regions with minimal

ice. The numbers correspond to the radar profiles in Figs. A-2 to A-5.

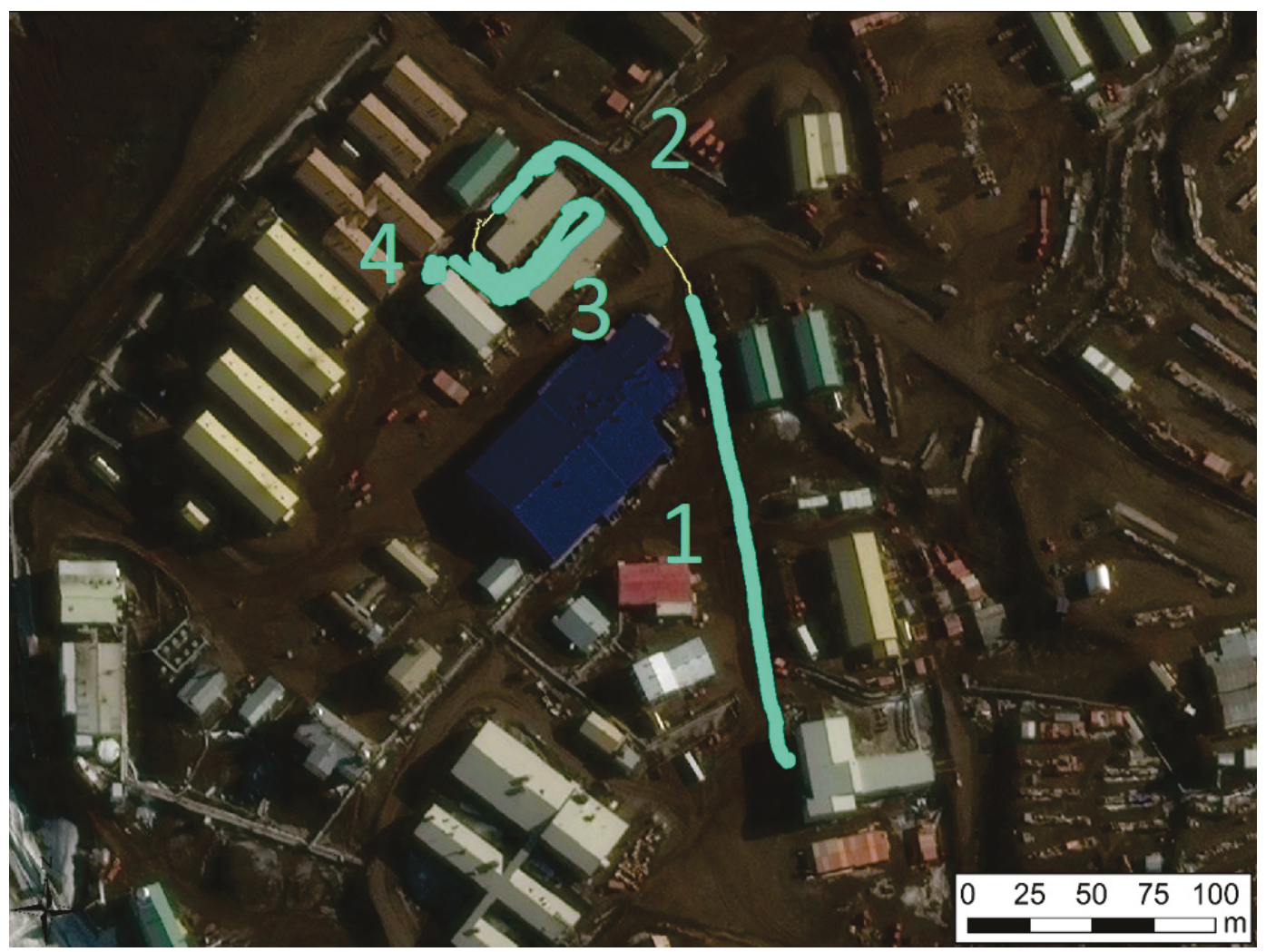

Figure A-2. GPR section 1 from Fig. A-1.

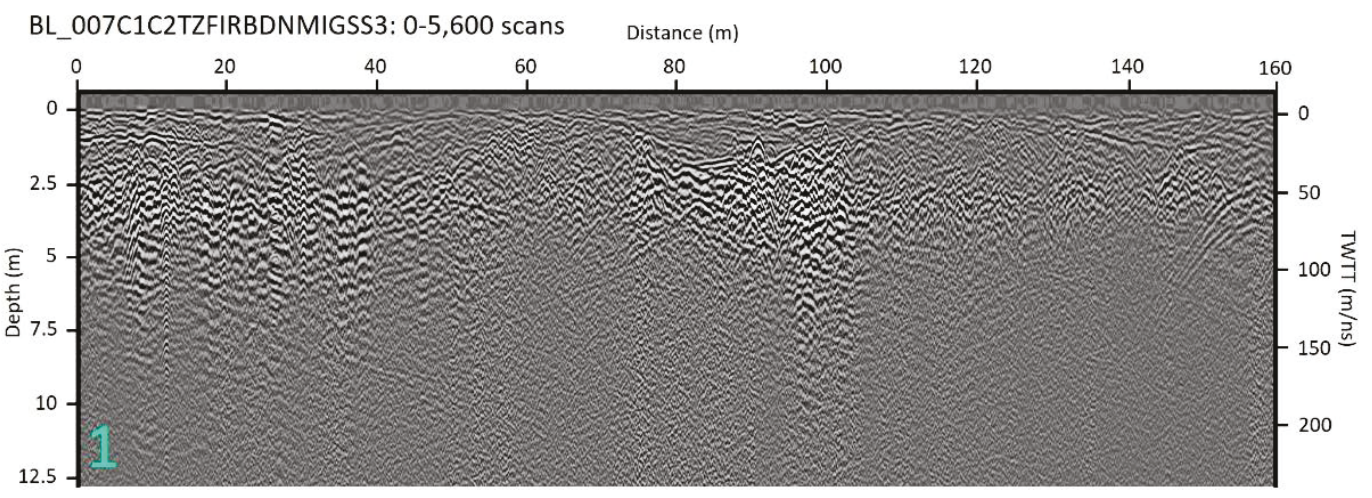


Figure A-3. GPR section 2 from Fig. A-1.

BL_007C1C2TZFIRBDNMIGSS3: 6,350-8,700 scans Distance $(\mathrm{m})$

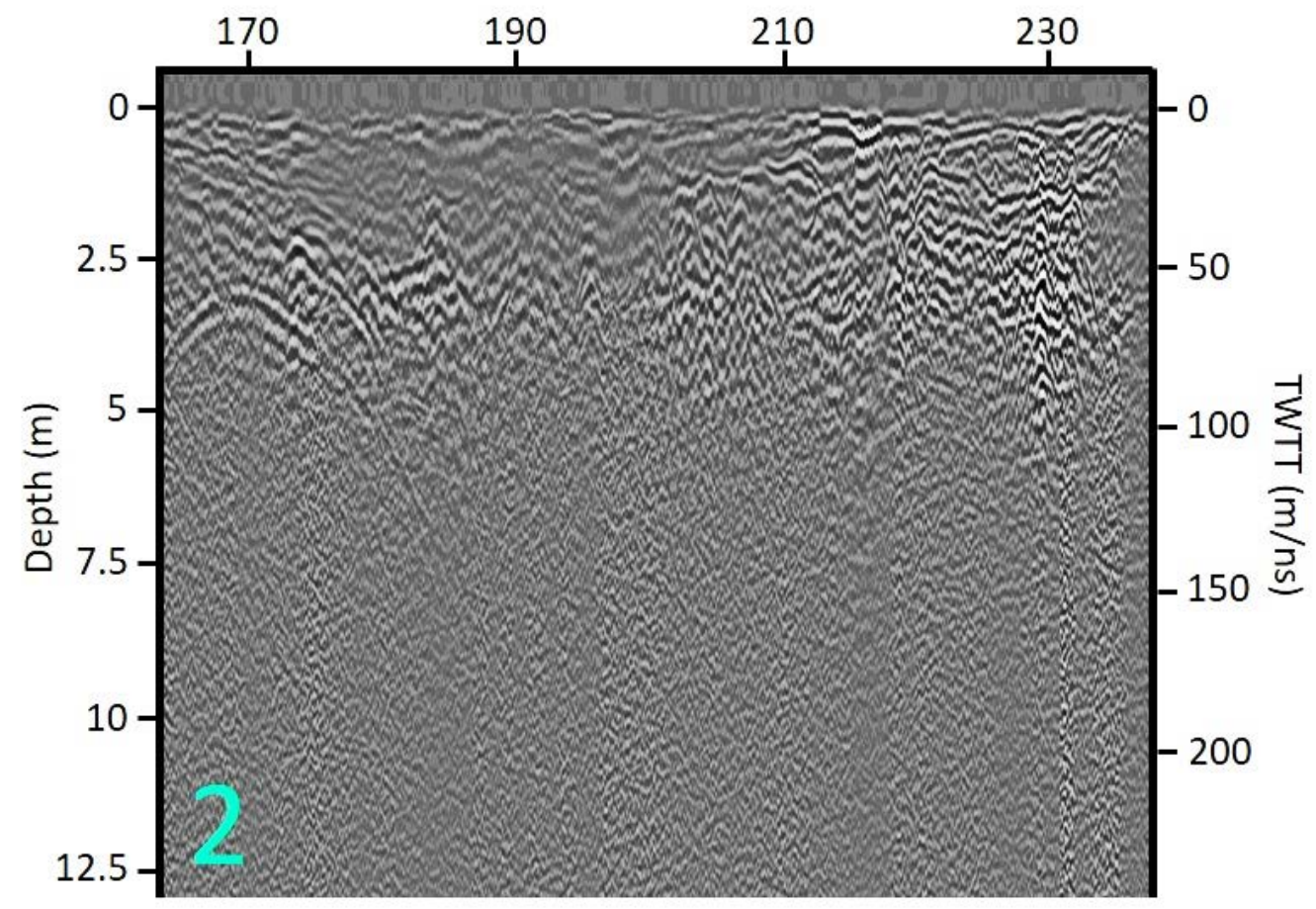

Figure A-4. GPR section 3 from Fig. A-1.

BL_007C1C2TZFIRBDNMIGSS3: 9,300-13,100 scans

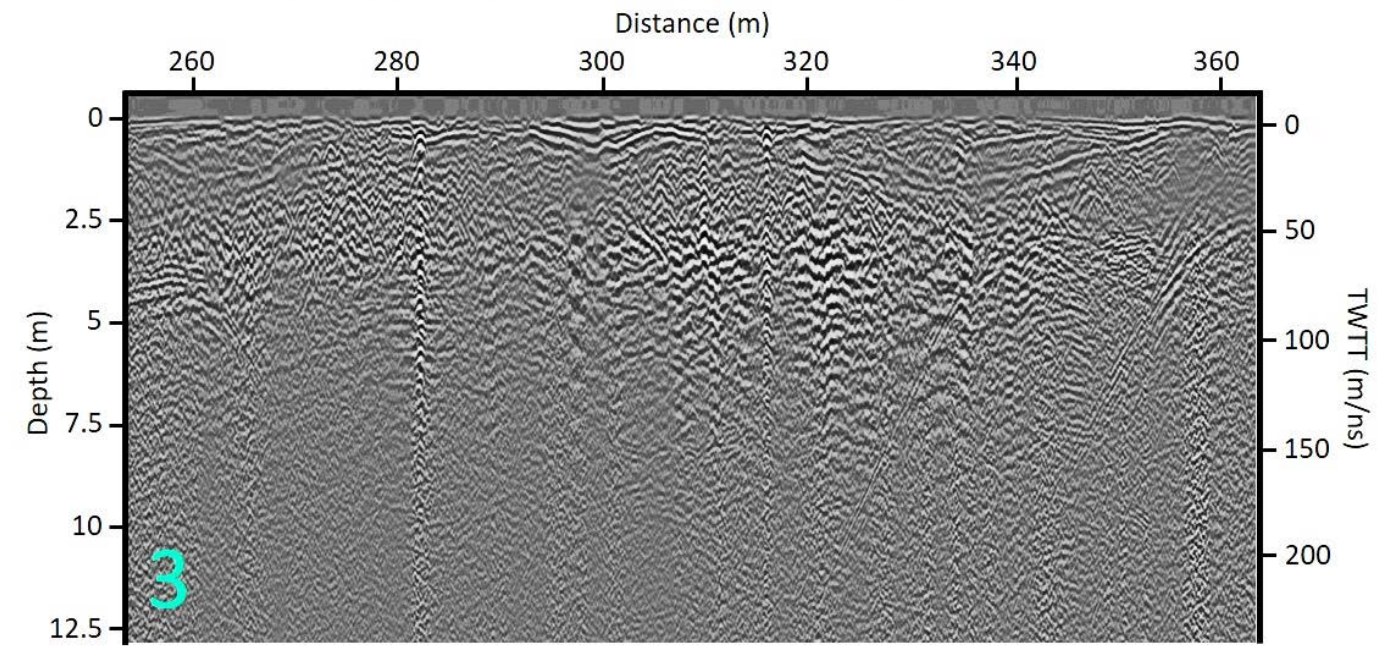


Figure A-5. GPR section 4 from Fig. A-1.

\section{BL_007C1C2TZFIRBDNMIGSS3: 16,400-18,200 scans}

\section{Distance $(\mathrm{m})$}

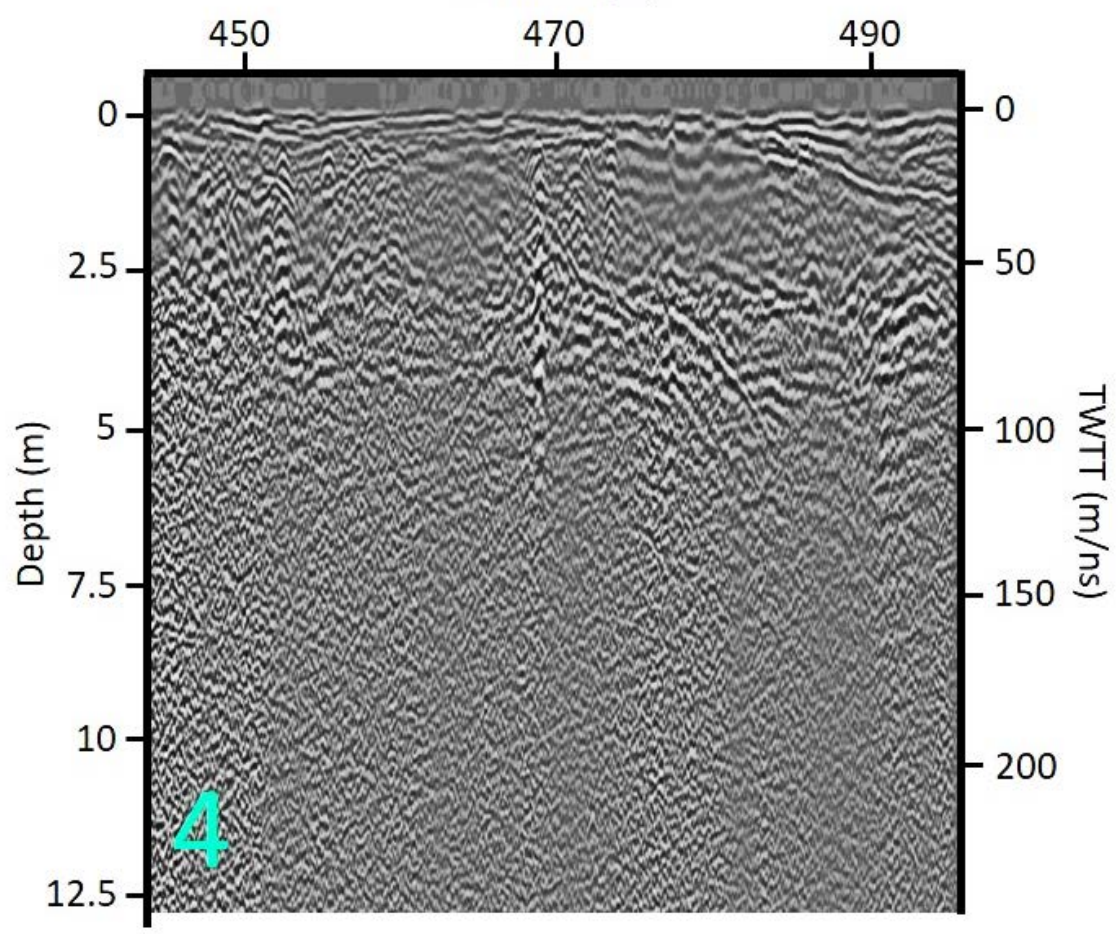

Figure A-6. Locator map for file BL008 GPR sections (Figs. A-7 to A-8) with blue lines denoting areas that contain excess or massive ice and yellow lines representing regions with minimal ice. The numbers correspond to the radar profiles in Figs. A-2 to A-5.

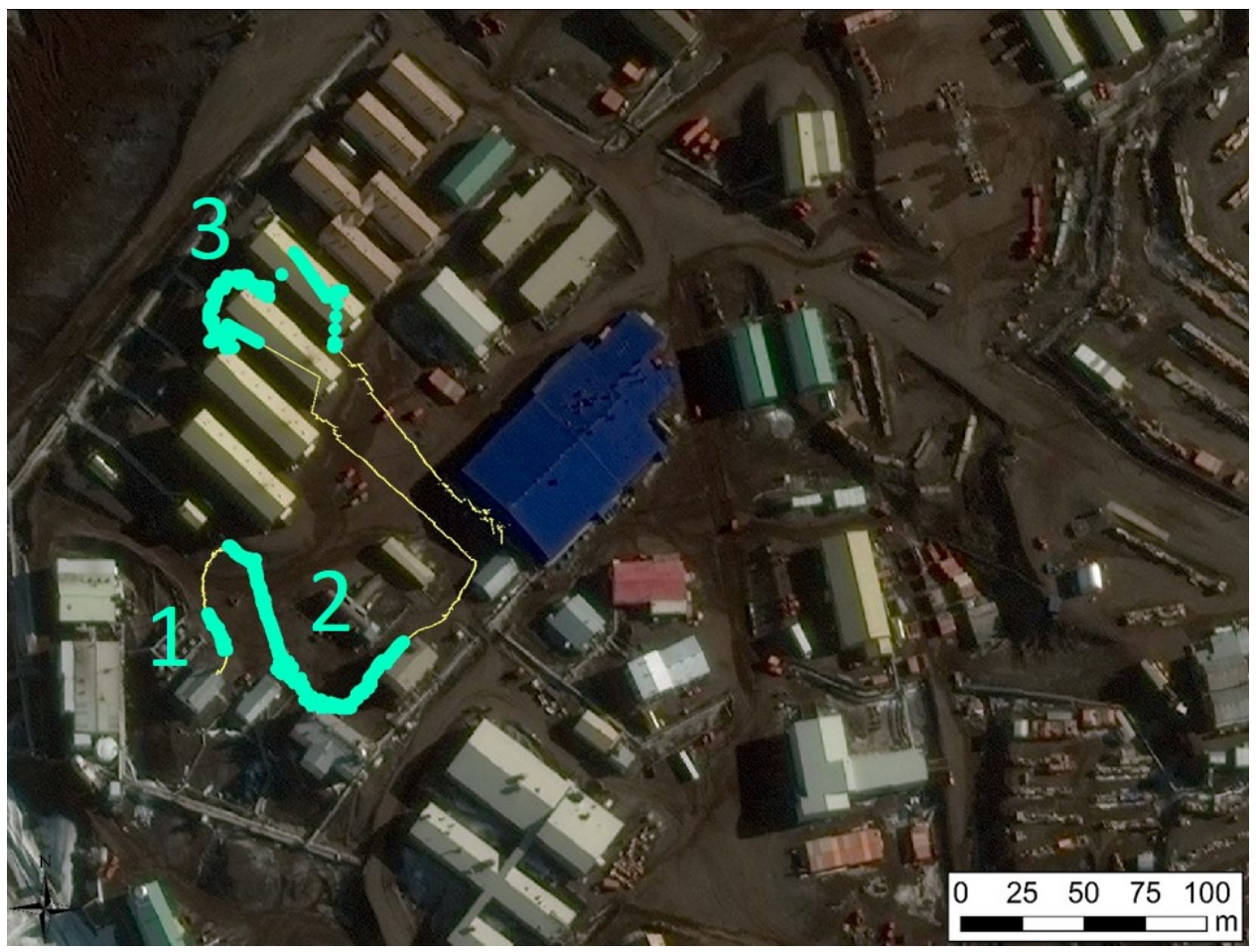


Figure A-7. GPR sections 1 and 2 from Fig. A-6.

BL_008C1C2TZFIRBGDNMIGSS3: 425-800 scans and 1,800-5,000 scans

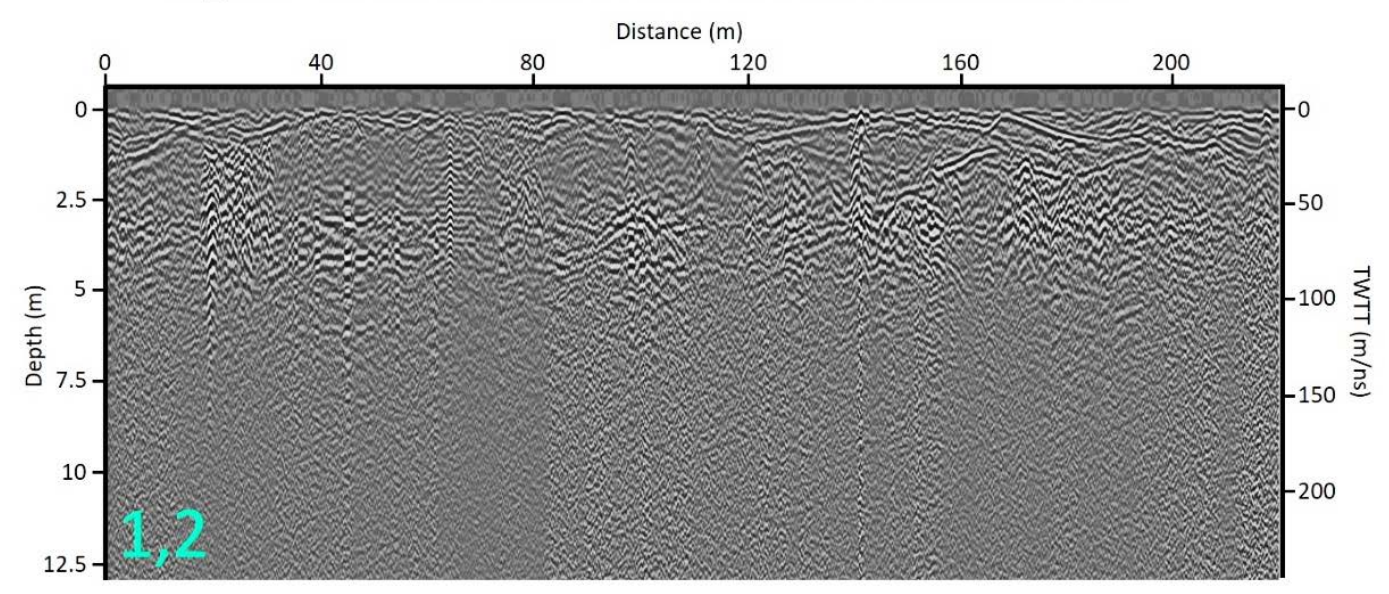

Figure A-8. GPR section 3 from Fig. A-6.

\section{BL_008C1C2TZFIRBGDNMIGSS3:9,200-11,700 scans}

Distance $(\mathrm{m})$

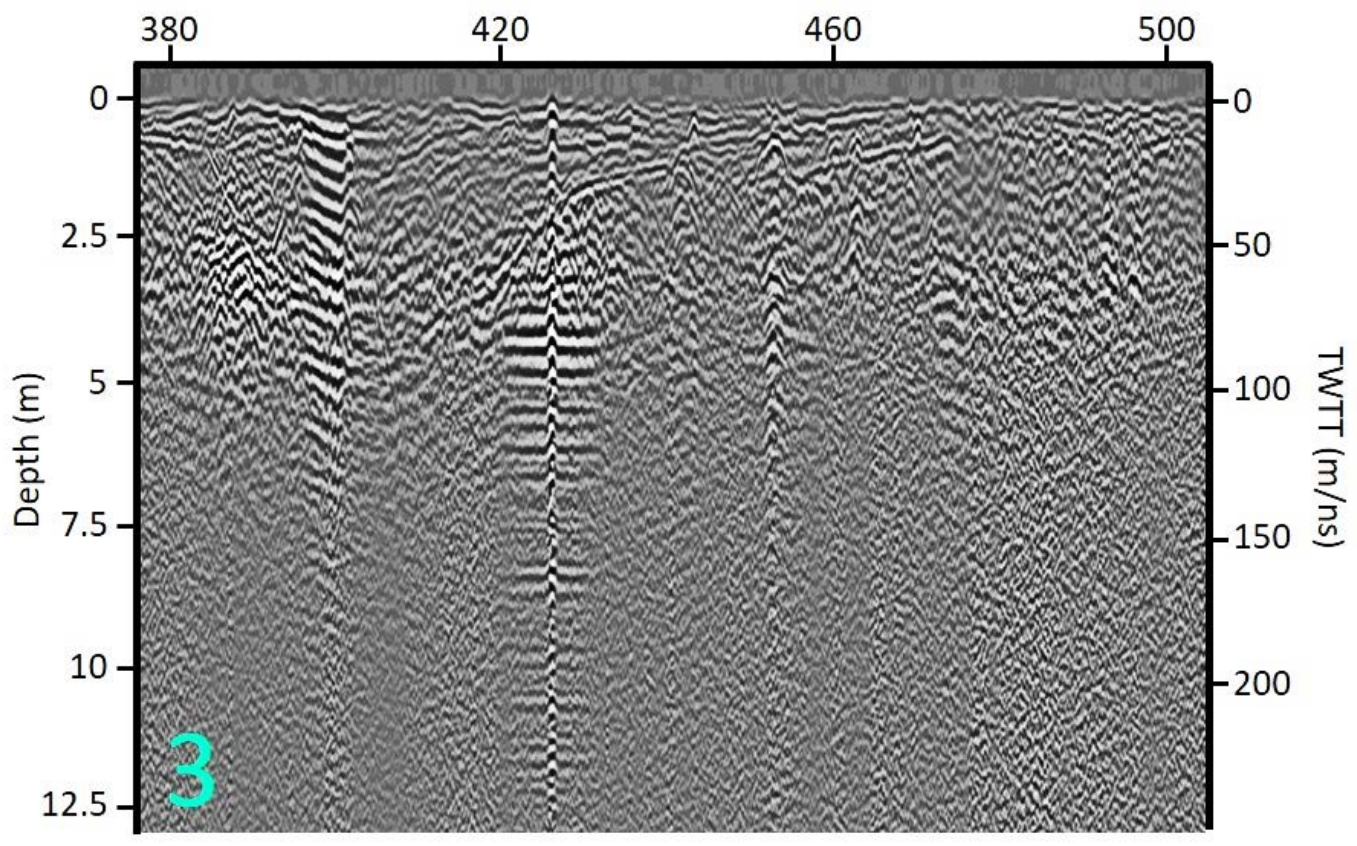


Figure A-9. Locator map for file BL010 GPR section (Fig. A-10) with blue lines denoting areas that contain excess or massive ice and yellow lines representing regions with minimal ice. The highlighted segment corresponds to the radar profile in Fig. A-2.

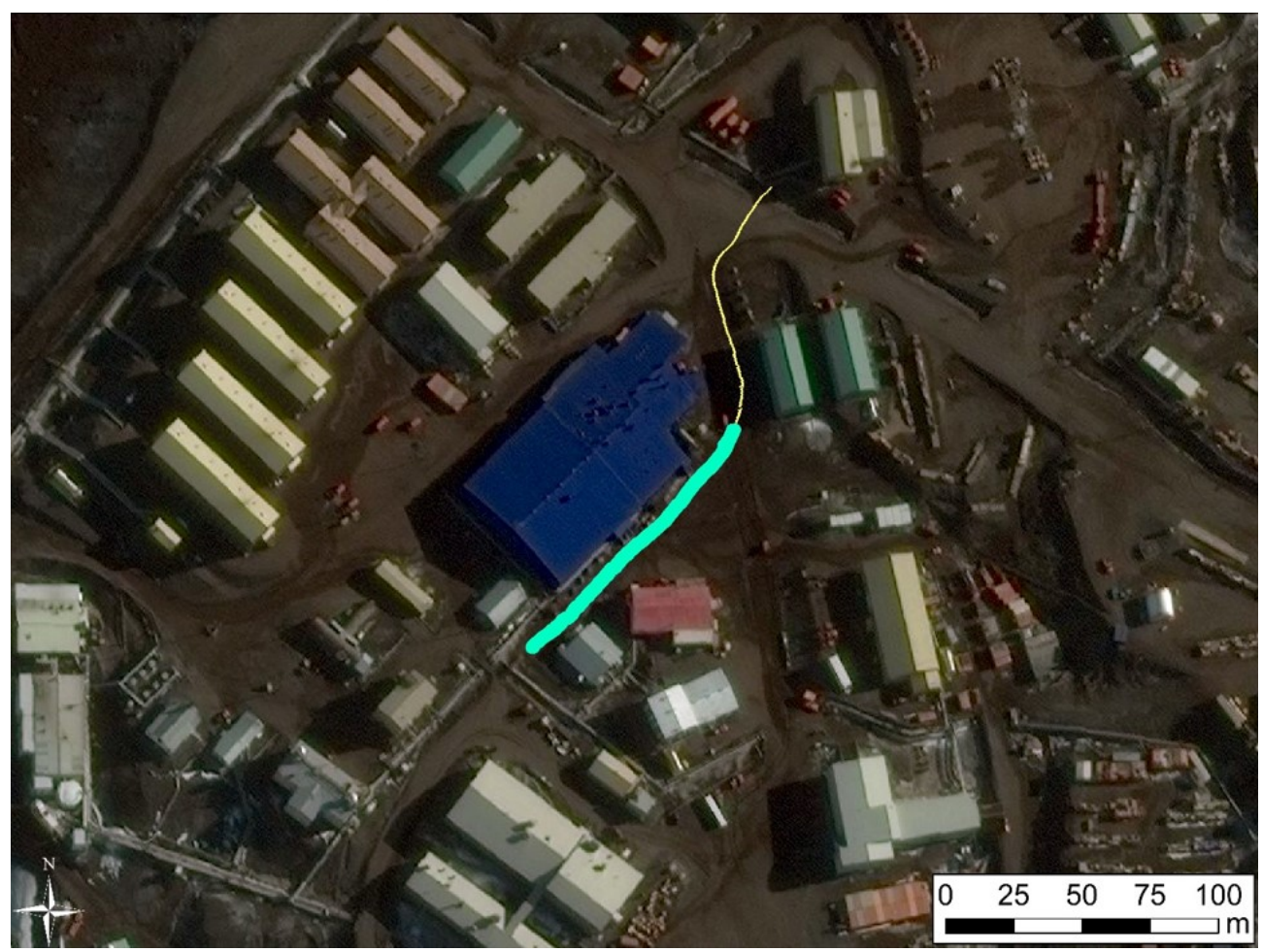

Figure A-10. GPR section shown from Fig. A-9.

BL_010C1C2TZDNFIRBGMIGSS3: 2,200-4,800 scans and whole profile Distance $(\mathrm{m})$

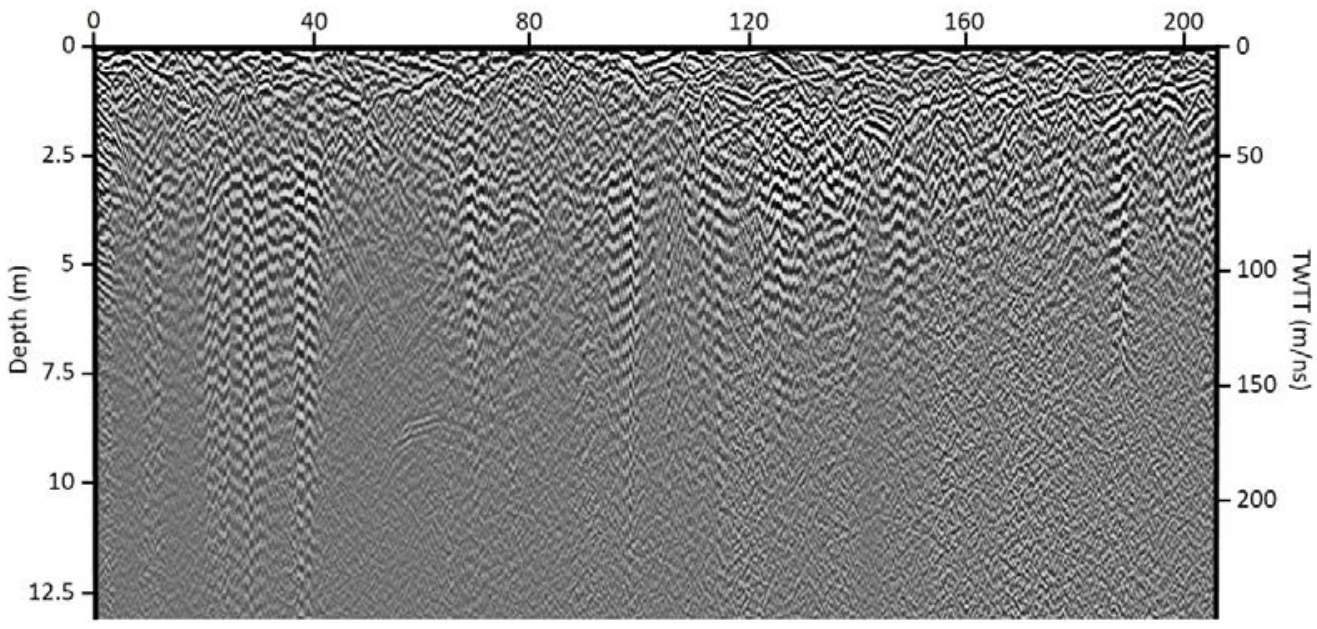


Figure A-11. Locator map for file BL011 GPR section (Figs. A-12 to A-13) with blue lines denoting areas that contain excess or massive ice and yellow lines representing regions with minimal ice. The numbers correspond to the radar profiles in Figs. A-2 to A-5.

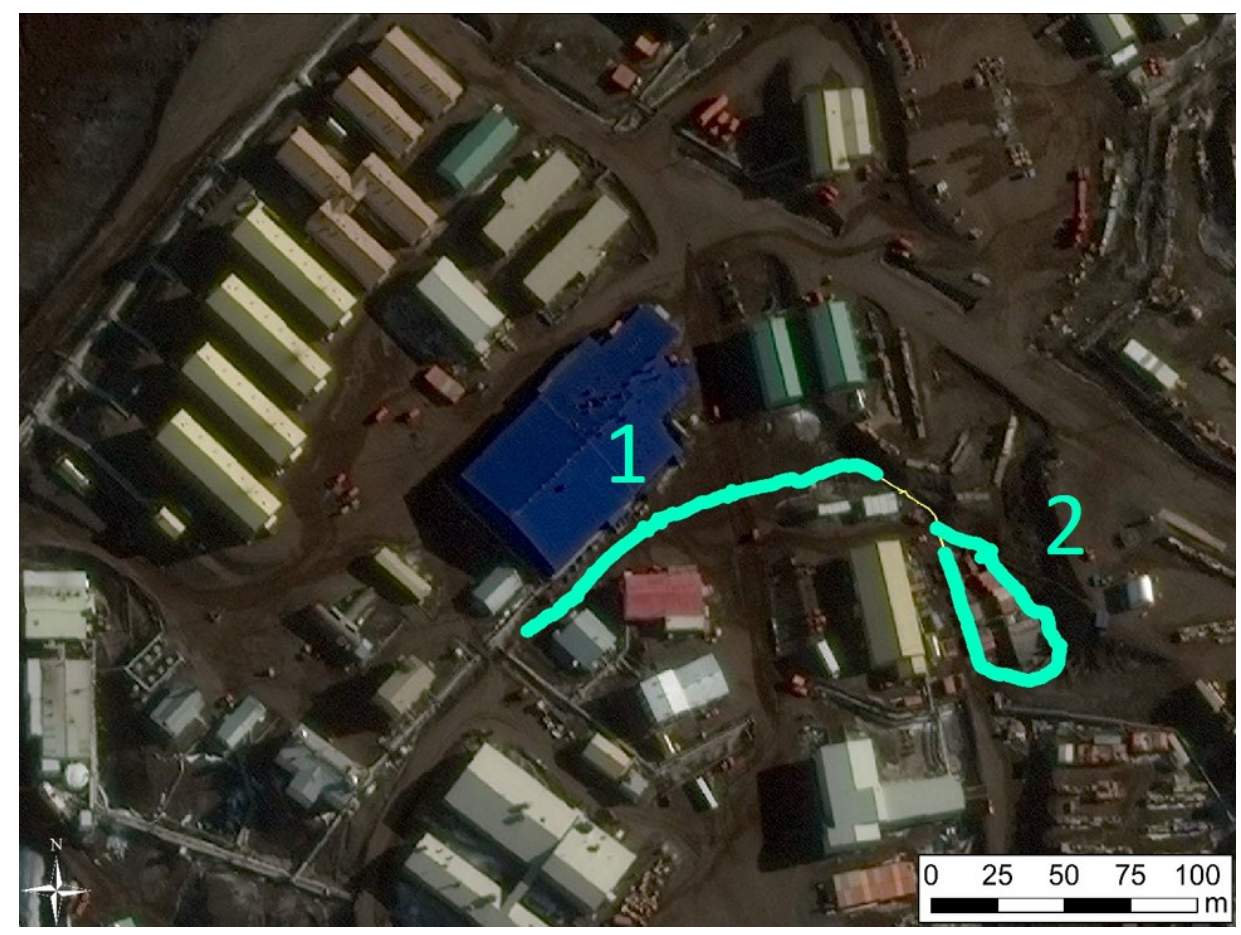

Figure A-12. GPR section 1 from Fig. A-11.

BL_011C1C2TZFIRBGDNMIGSS3: 0-3,900 scans Distance $(m)$

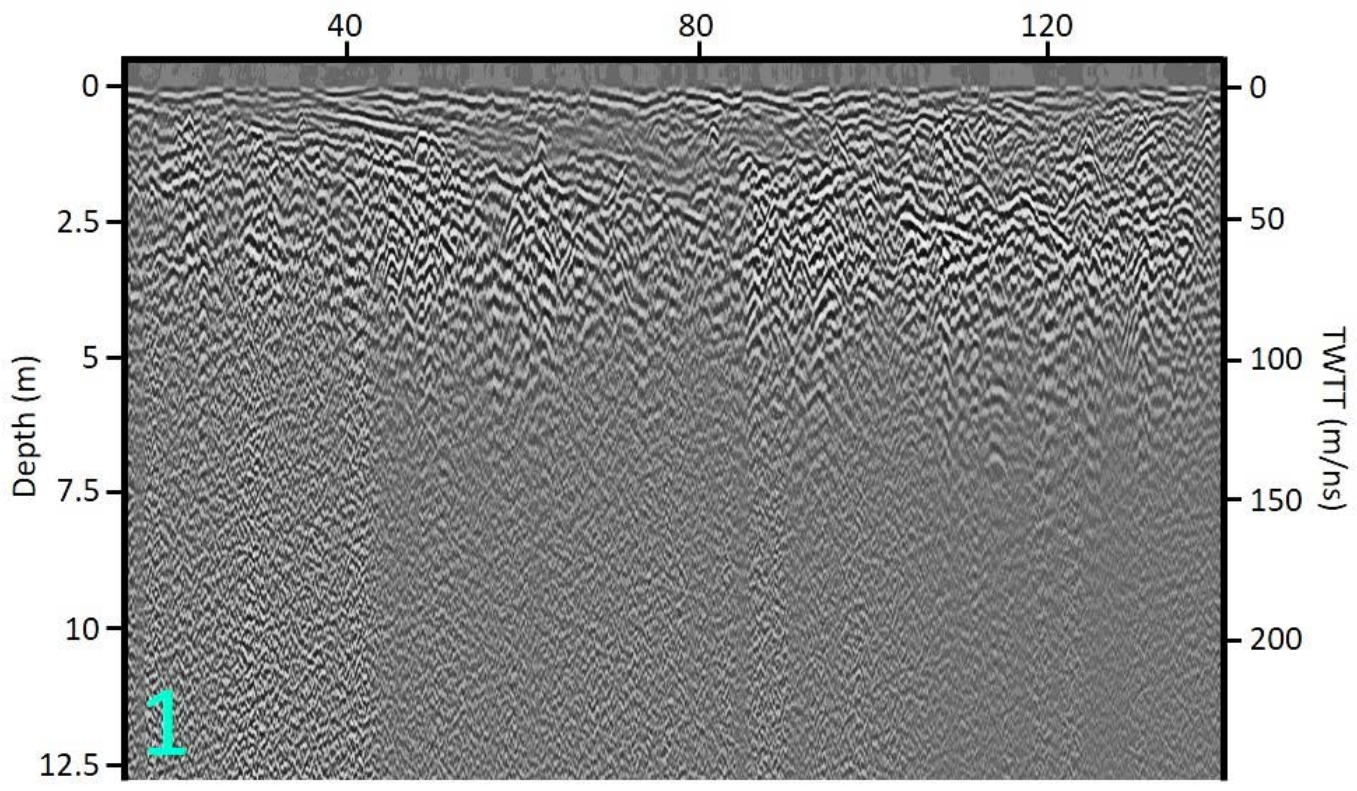


Figure A-13. GPR section 2 from Fig. A-11.

BL_011C1C2TZFIRBGDNMIGSS3: 4,900-9,400 scans

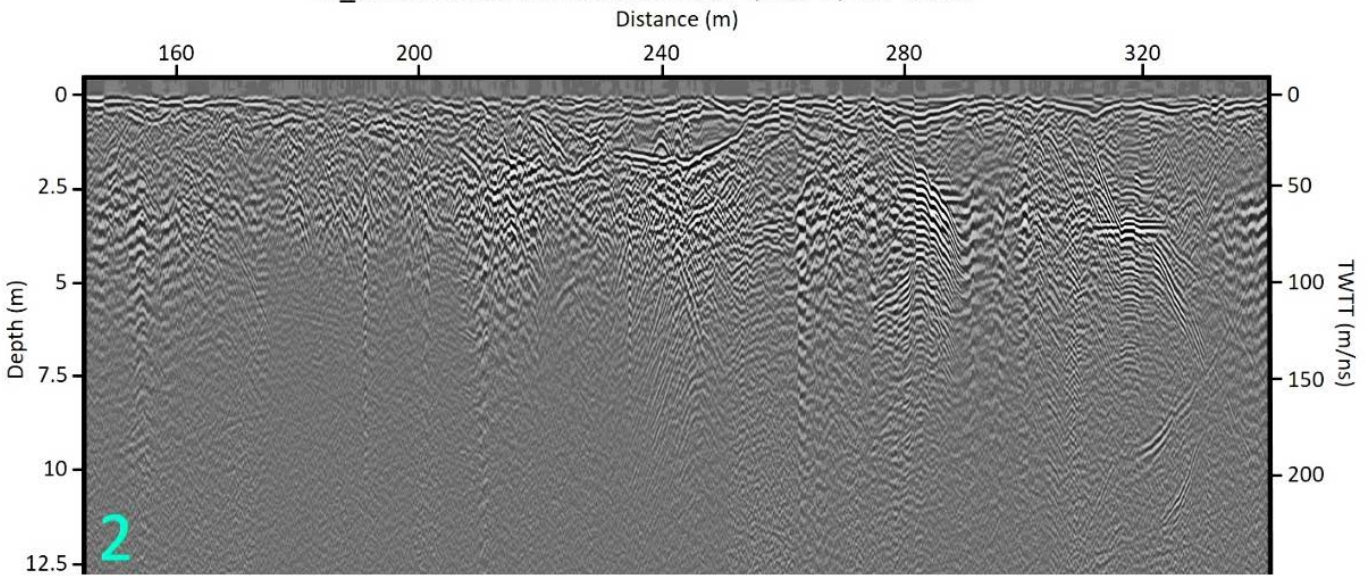

Figure A-14. Locator map for file BL012 GPR sections (Figs. A-15 to A-19) with blue lines denoting areas that contain excess or massive ice and yellow lines representing regions with minimal ice. The numbers correspond to the radar profiles in Figs. A-2 to A-5.

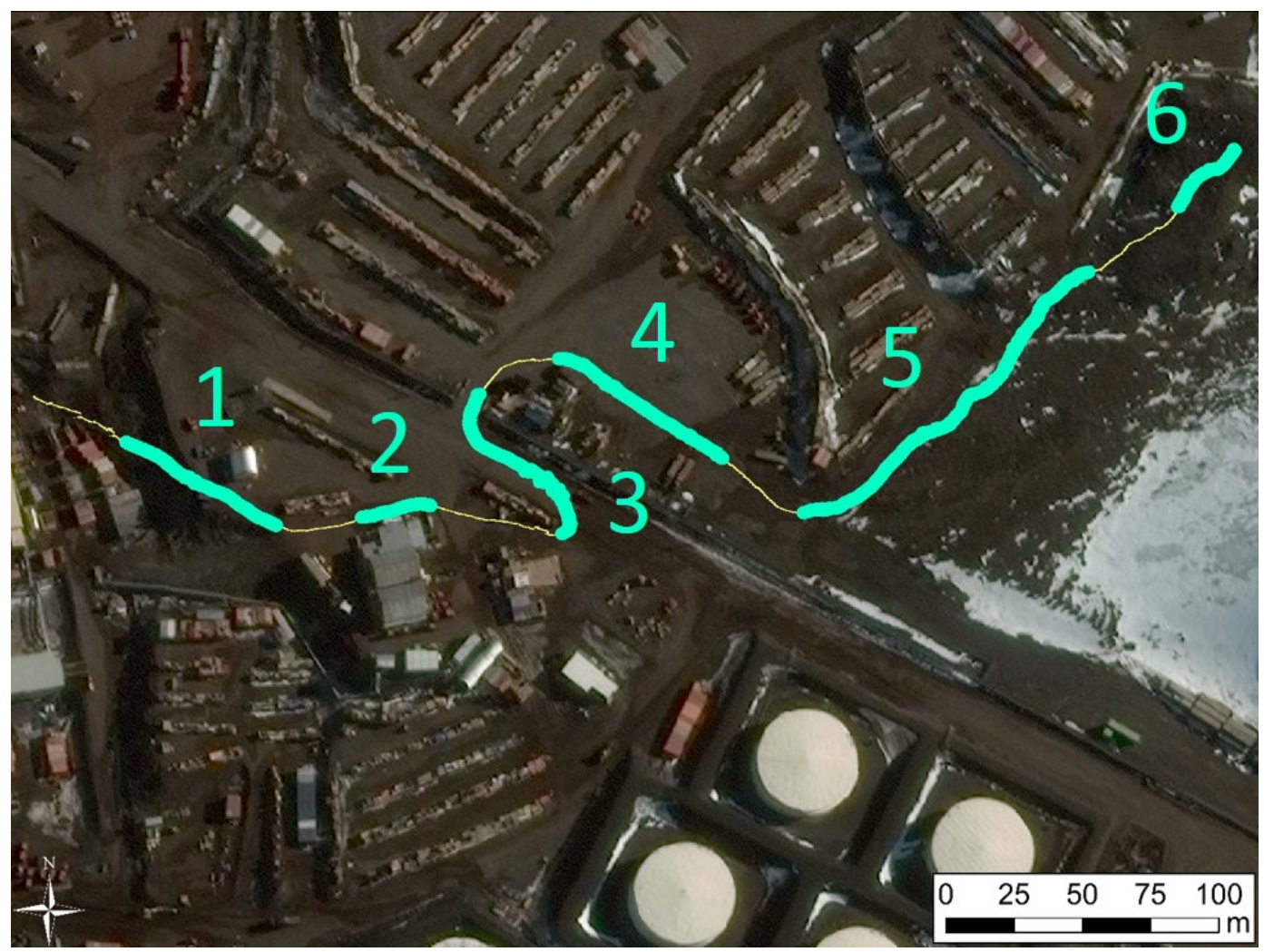


Figure A-15. GPR section 1 from Fig. A-14.

BL_012C1C2TZBGFIRDNMIGSS3: 1,200-3,050 scans

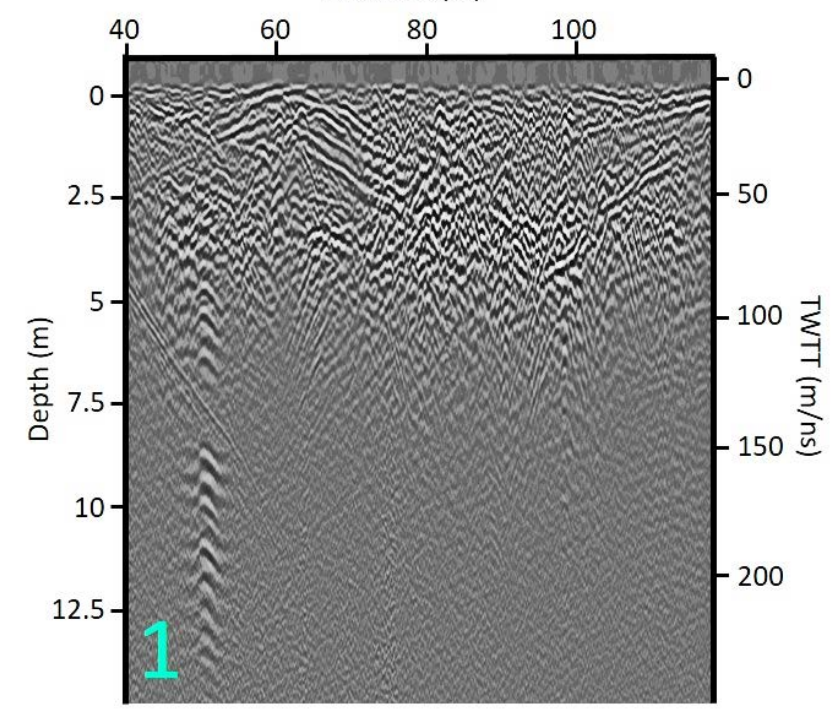

Figure A-16. GPR section 2 from Fig. A-14.

\section{BL_012C1C2TZBGFIRDNMIGSS3 3,800-4,400 scans}

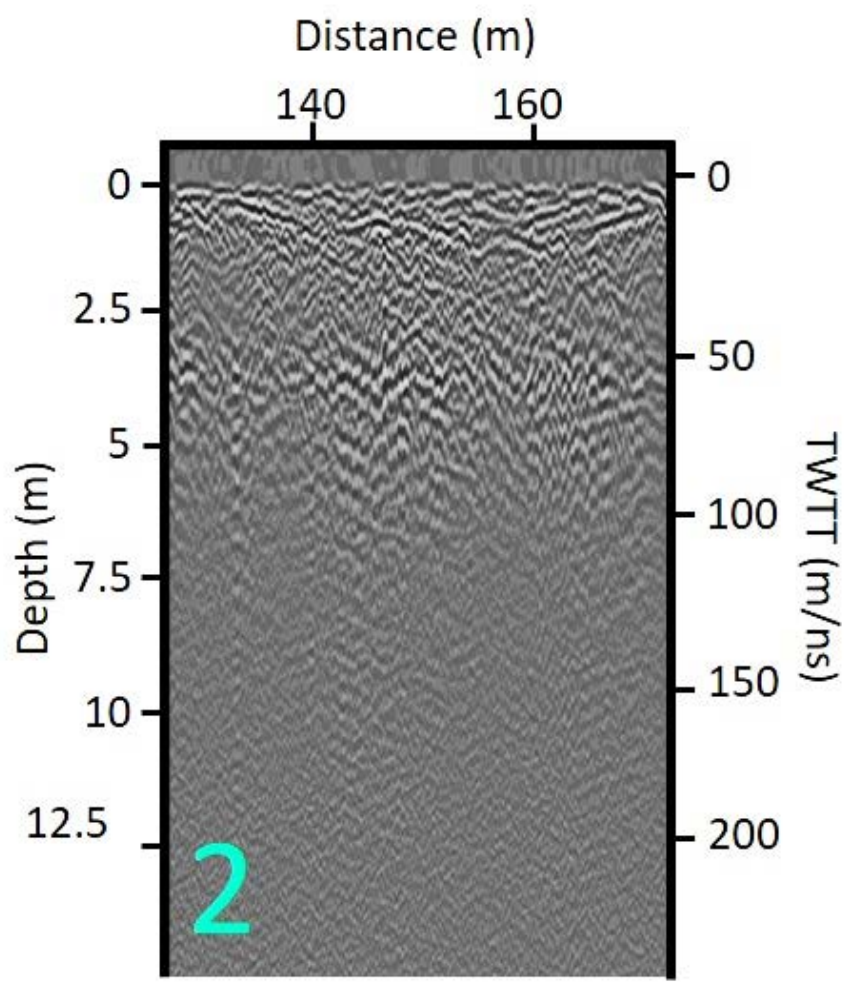


Figure A-17. GPR sections 3 and 4 from Fig. A-14.

BL_012C1C2TZBGFIRDNMIGSS3 5,500-7,100 and 7,900-9,450 scans

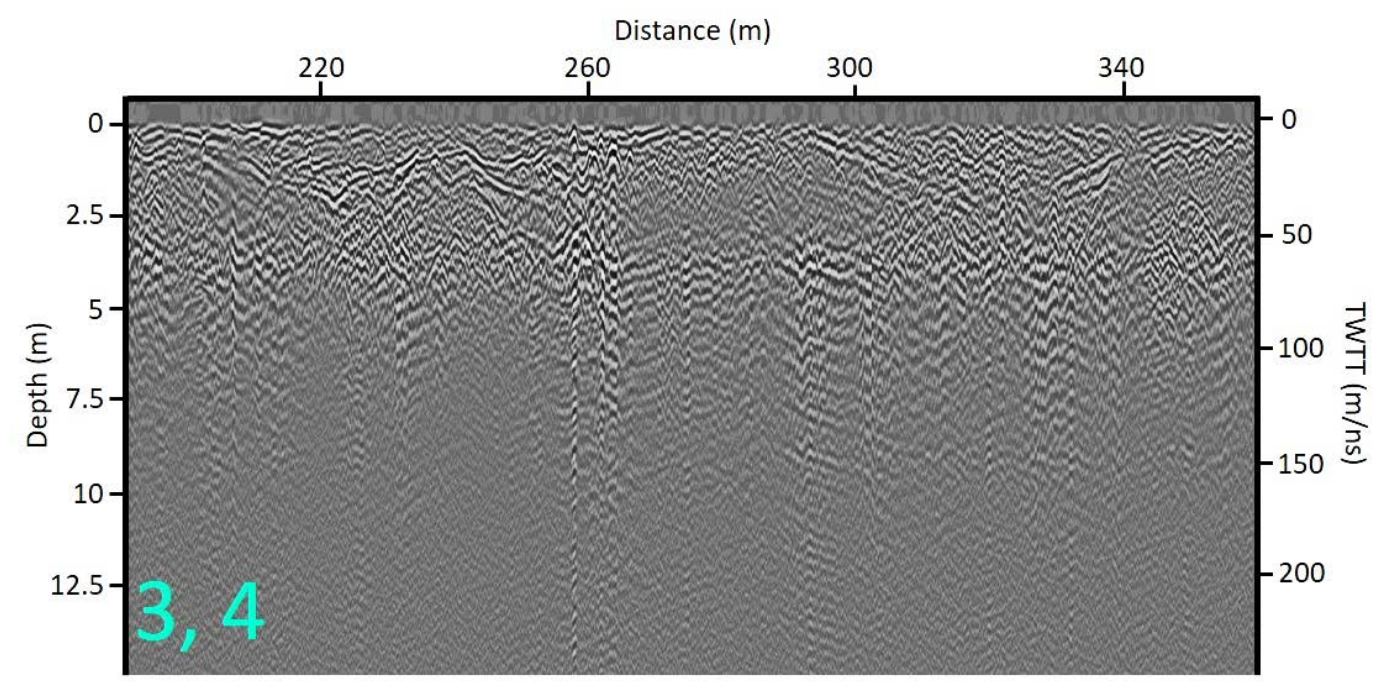

Figure A-18. GPR section 5 from Fig. A-14.

BL_012C1C2TZBGFIRDNMIGSS3 10,300-14,400 scans

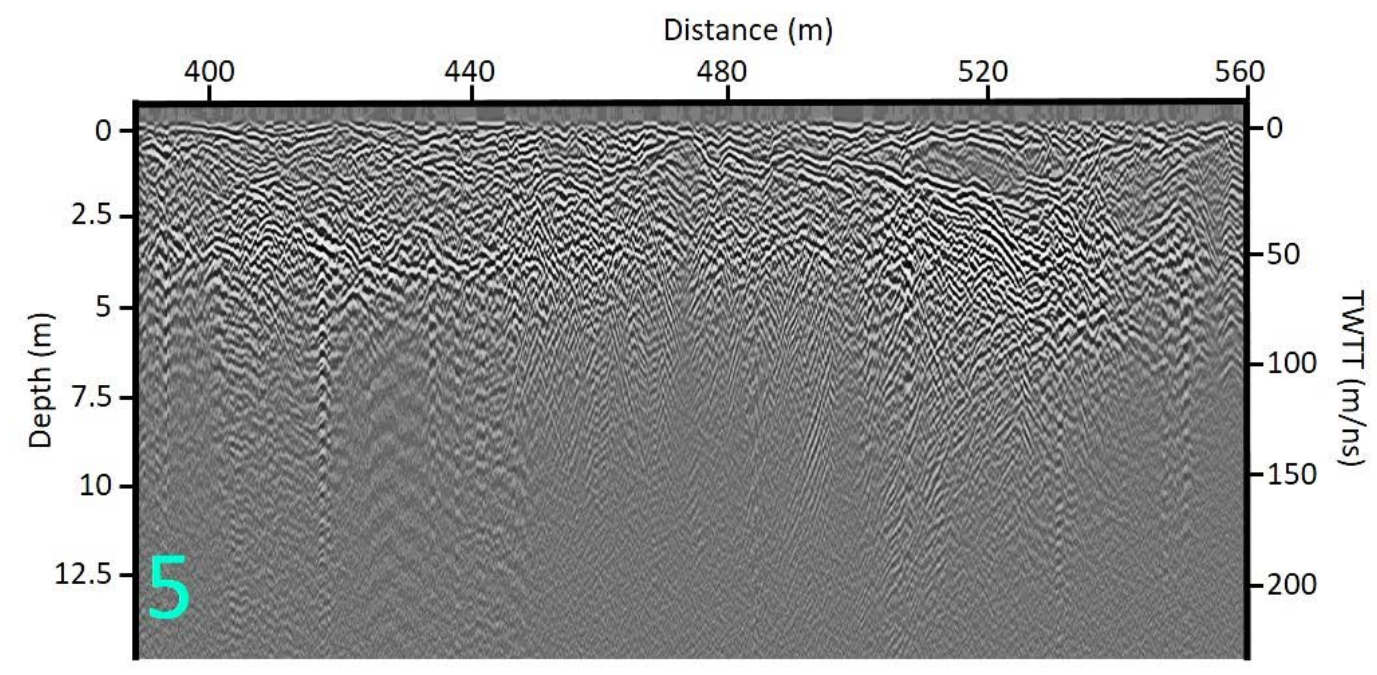


Figure A-19. GPR section 6 from Fig. A-14.

\section{BL_012C1C2TZBGFIRDNMIGSS3 15,800-16,860 scans}

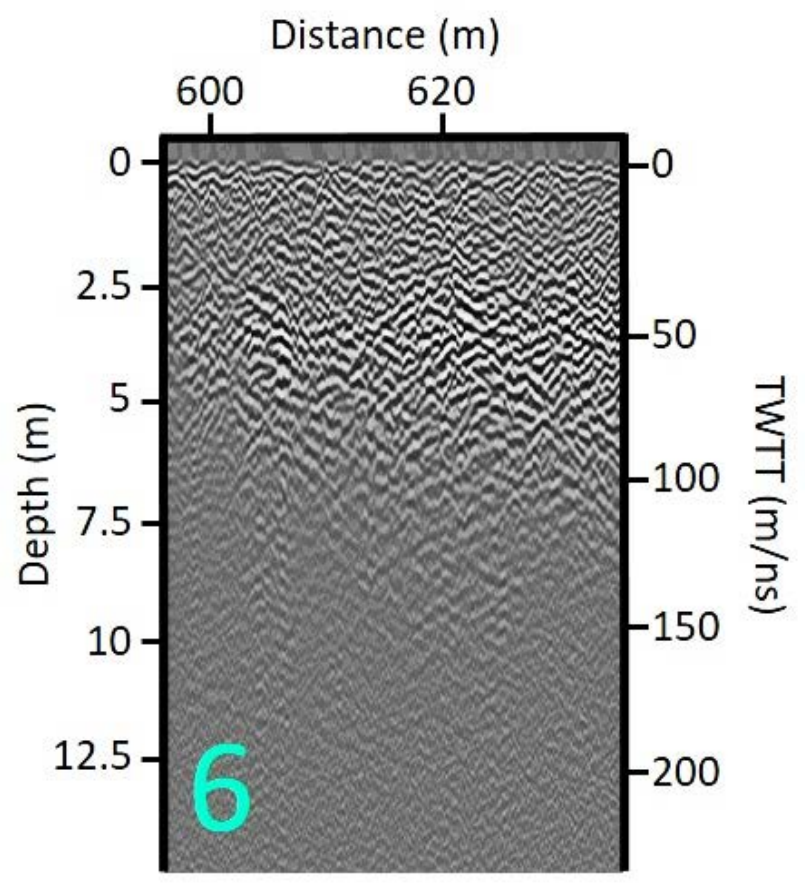

Figure A-20. Locator map for file BL015 GPR sections (Figs. A-21 to A-24) with blue lines denoting areas that contain excess or massive ice and yellow lines representing regions with minimal ice. The numbers correspond to the radar profiles in Figs. A-2 to A-5.

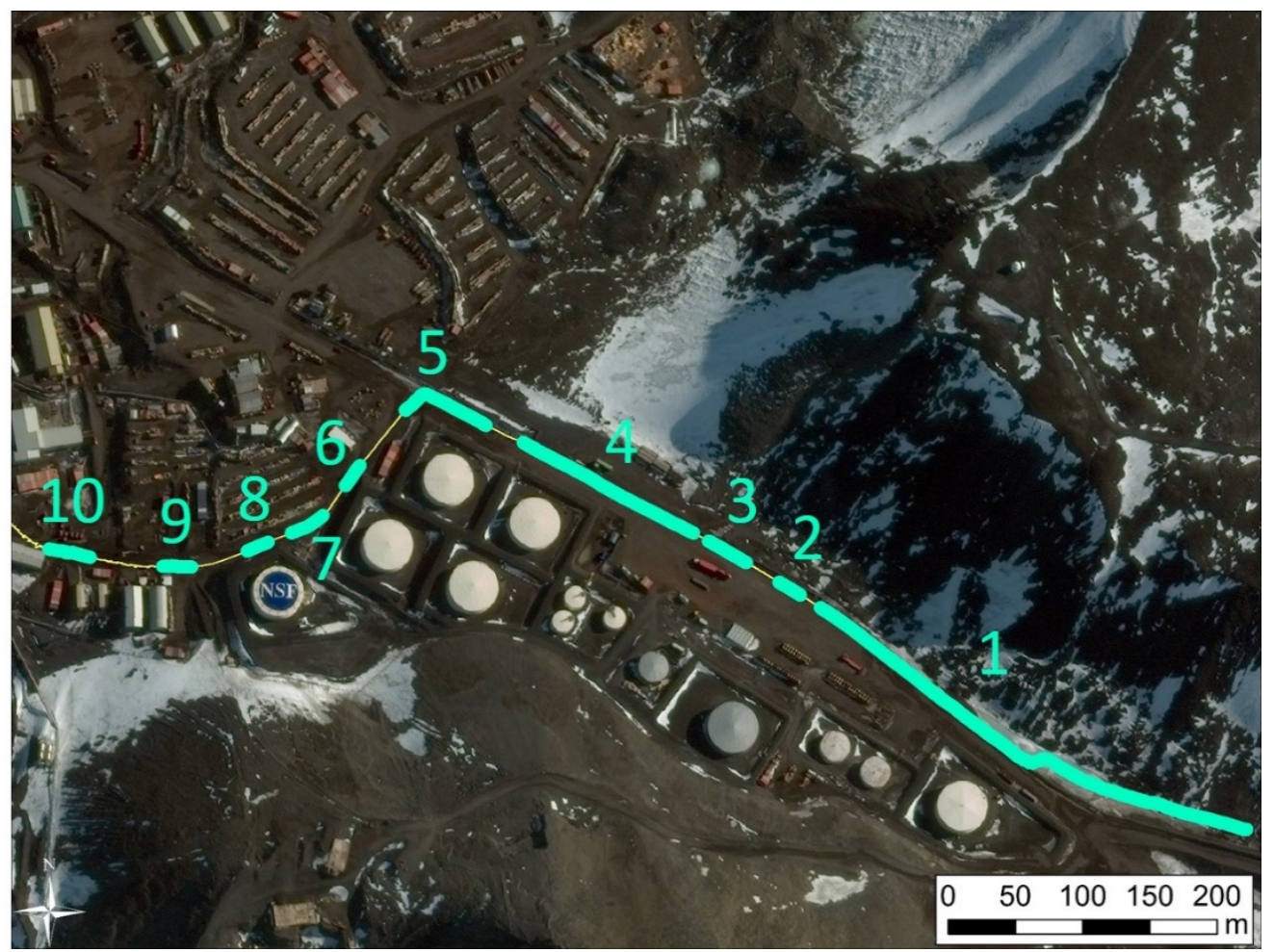


Figure A-21. GPR section 1 from Fig. A-20.

BL_015C1C2TZFIRBGDNMIGSS3 0-8,700 scans

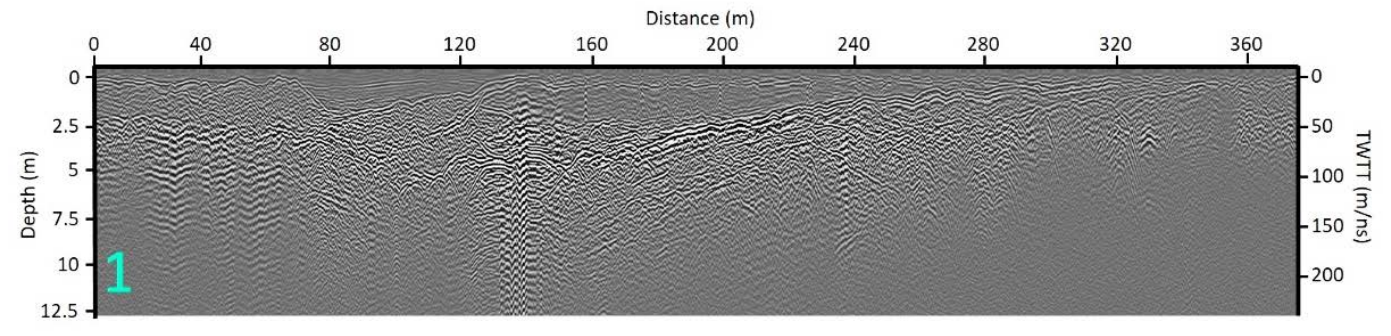

Figure A-22. GPR sections 2, 3, and 4 from Fig. A-20.

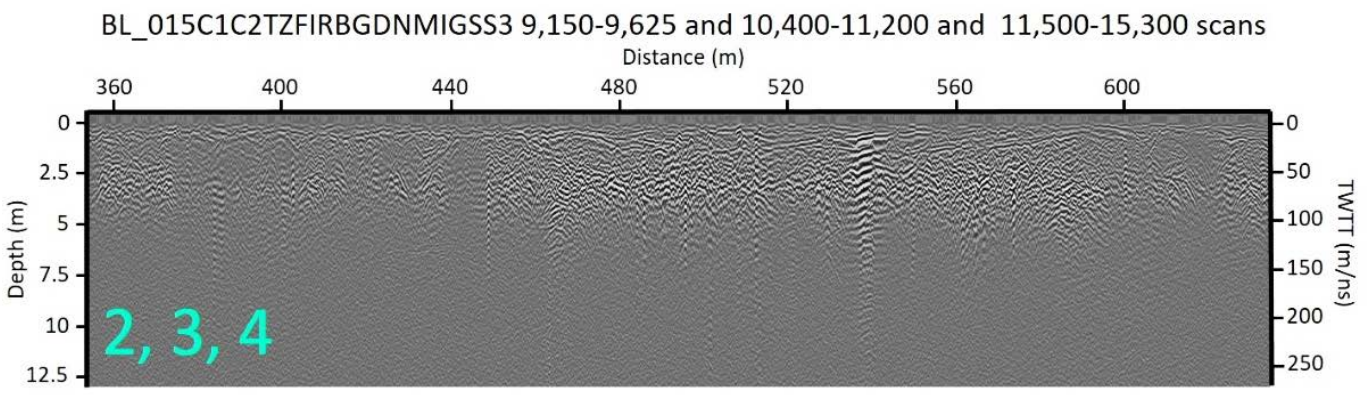

Figure A-23. GPR section 5, 6, and 7 from Fig. A-20.

BL_015C1C2TZFIRBGDNMIGSS3 16,000-17,800 and 19,000-19,500 and 20,300- 21,050 scans

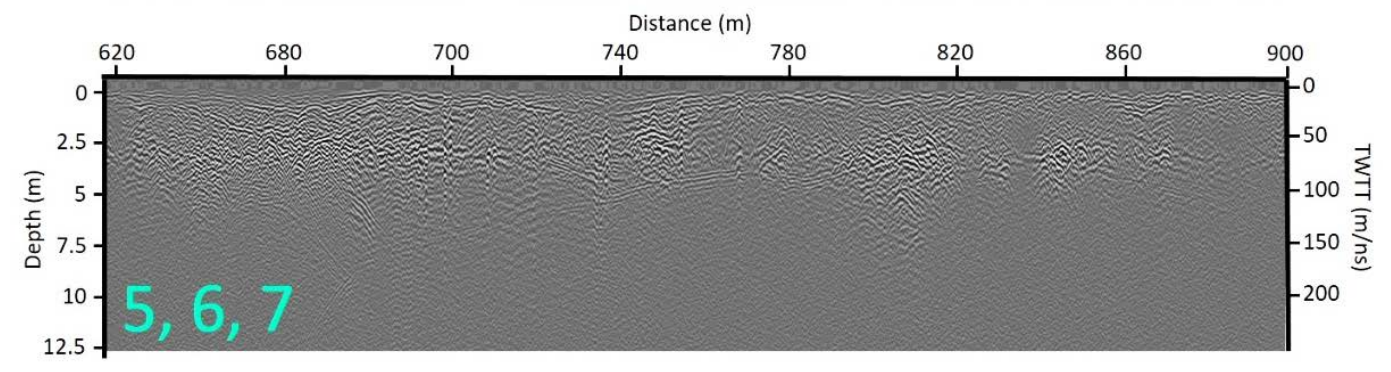

Figure A-24. GPR sections 8, 9, and 10 from Fig. A-20.

BL_015C1C2TZFIRBGDNMIGSS3 21,555-21,950 and 23,000-23,550 and 25,095-25,900 scans

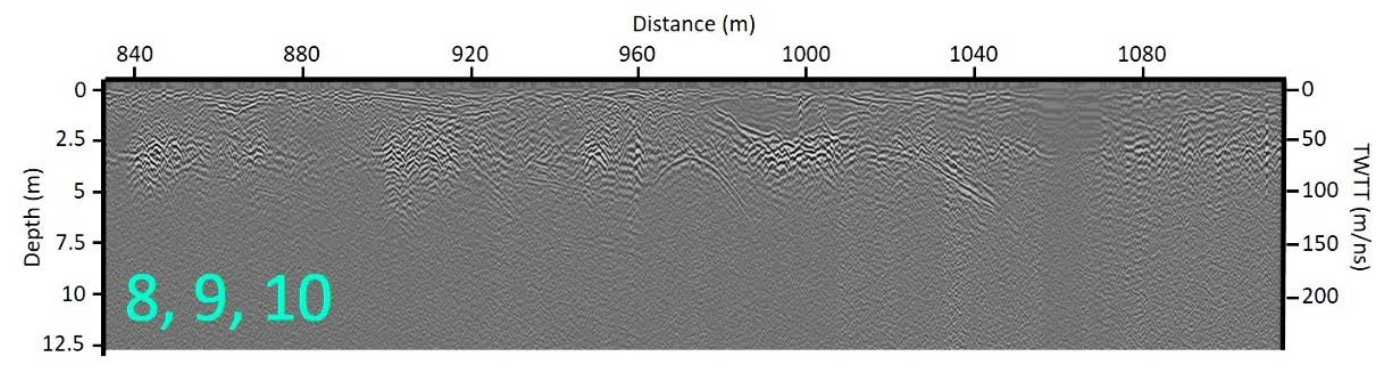


Figure A-25. Locator map for file BL016 GPR sections (Fig. A-26) with blue lines denoting areas that contain excess or massive ice and yellow lines representing regions with minimal ice.

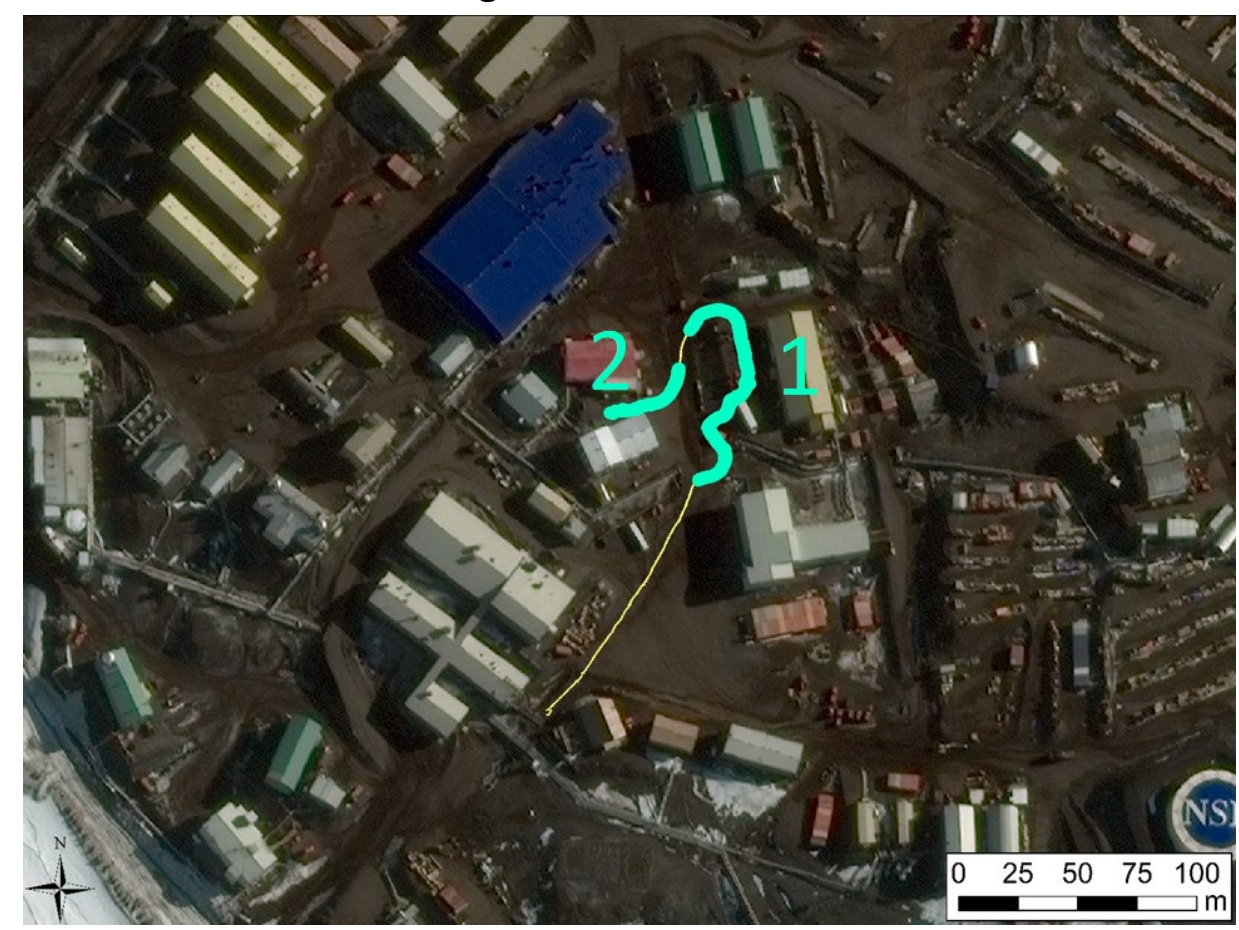

Figure A-26. GPR sections 1 and 2 from Fig. A-25.

BI_016C1C2C3TZFIRBGDNS3: 3,500-6,900 and 7,300-8,200 scans

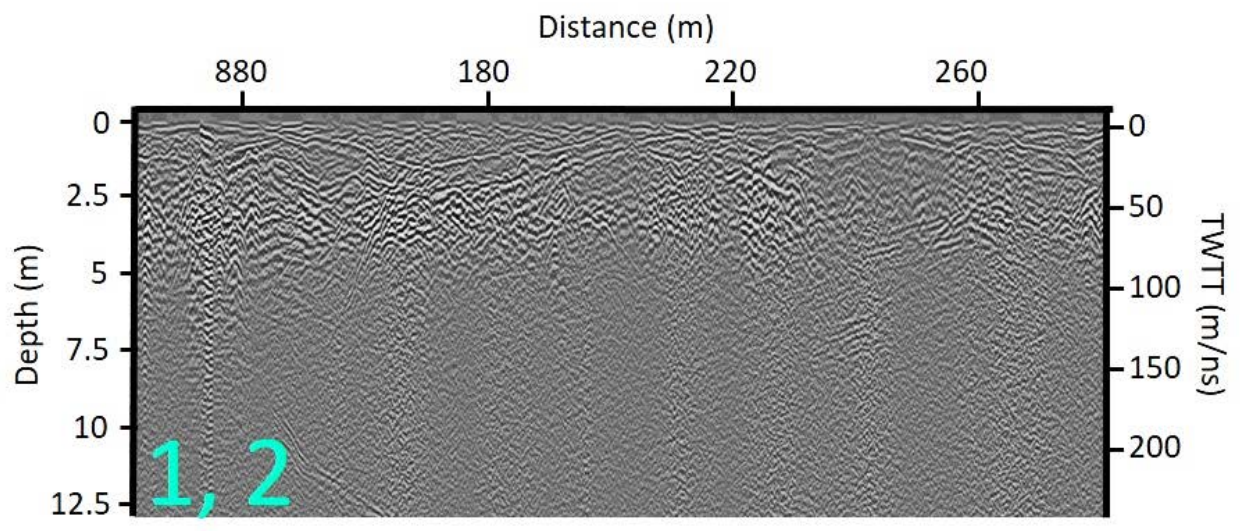


Figure A-27. Locator map for file BL017 GPR sections (Fig. A-28) with blue lines denoting areas that contain excess or massive ice and yellow lines representing regions with minimal ice. The numbers correspond to the radar profile in Fig. A-2.

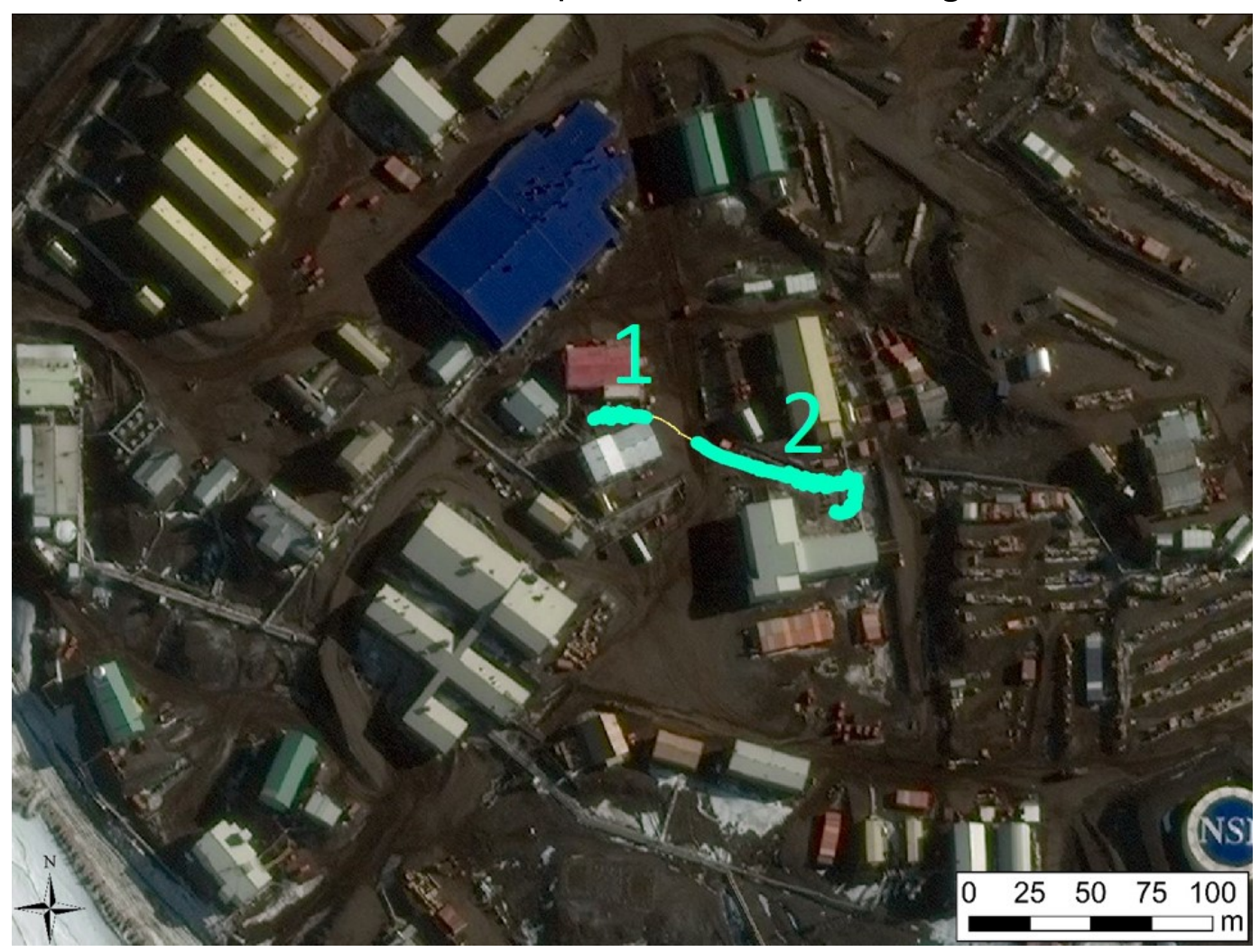

Figure A-28. GPR sections 1 and 2 from Fig. A-27.

\section{BL_017C1C2TZFIRBGDNMIGS3: 0-600 and 1,100-3,100}

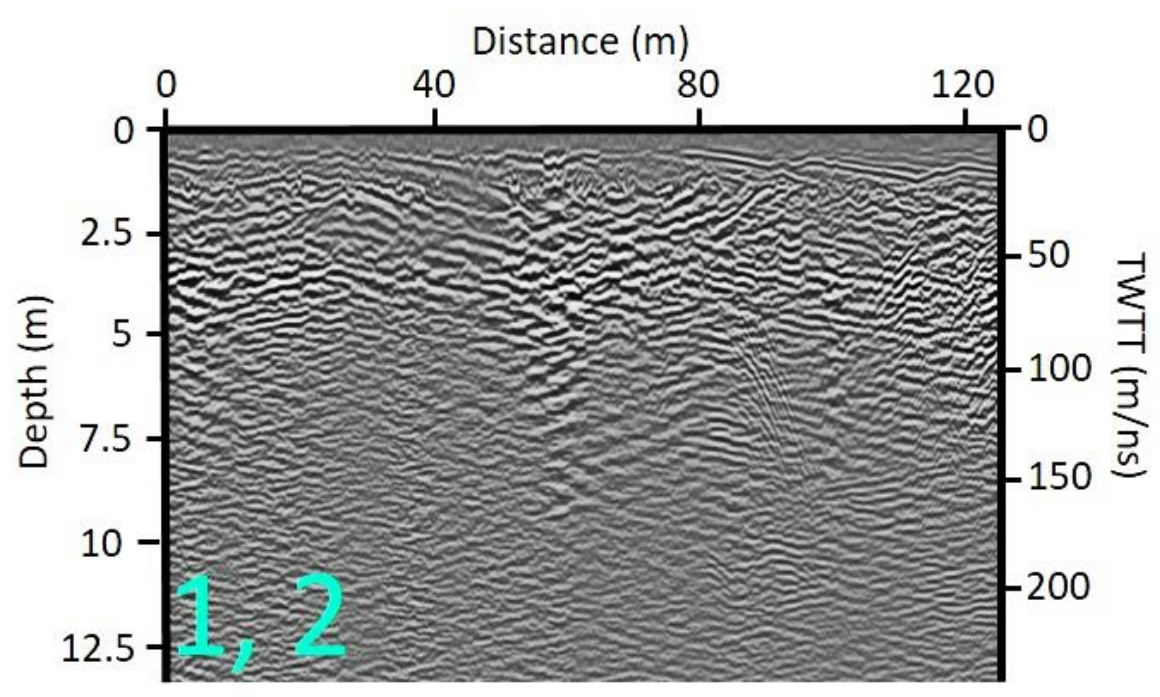


Figure A-29. Locator map for file MCM002 GPR section (Fig. A-30) with blue lines denoting areas that contain excess or massive ice and yellow lines representing regions with minimal

ice. The highlighted segment corresponds to the radar profile in Fig. A-2.

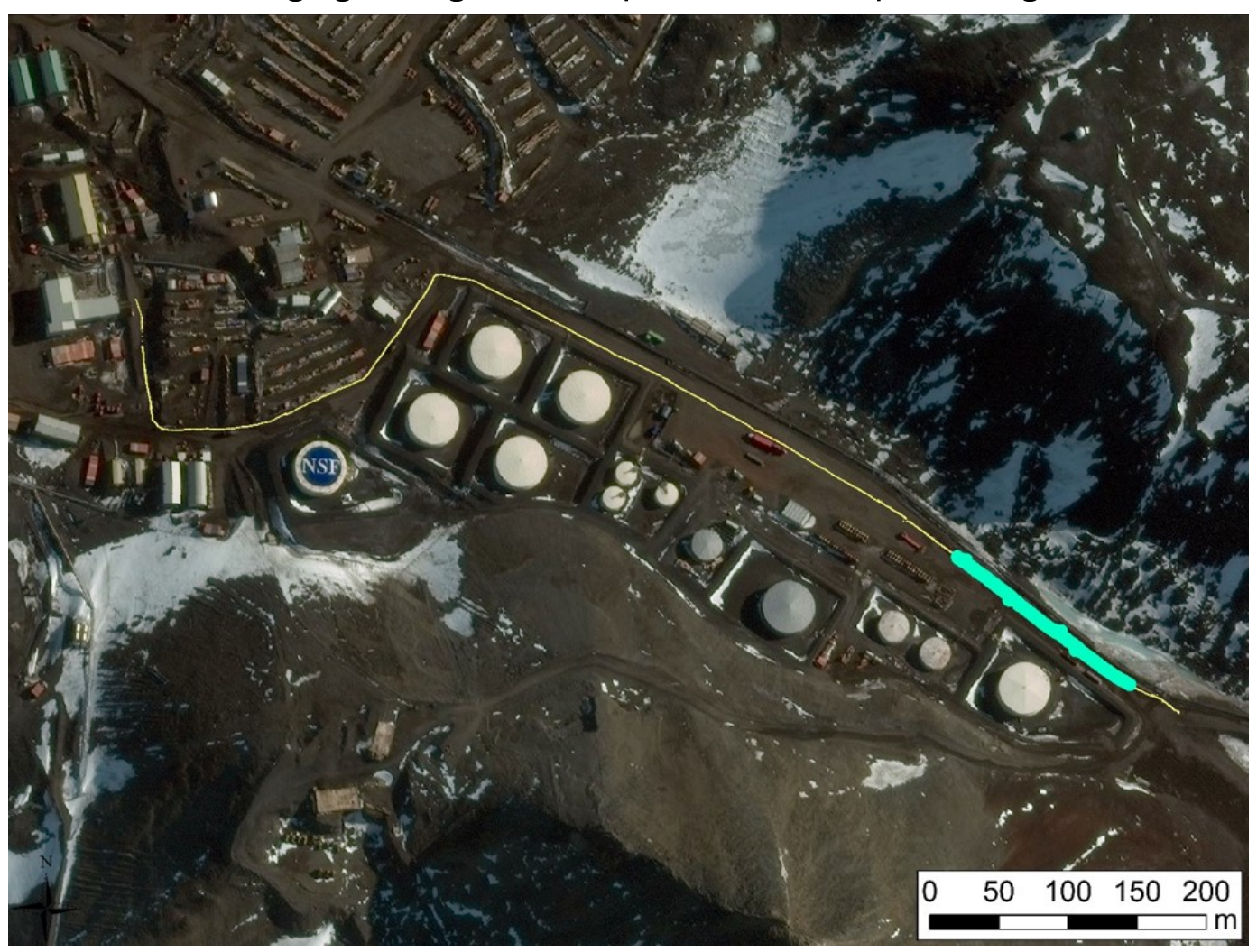

Figure A-30. GPR section from Fig. A-29.

MCM_002C1C2TZFIRBGDNMIGSS3 21,360- 24,660 scans

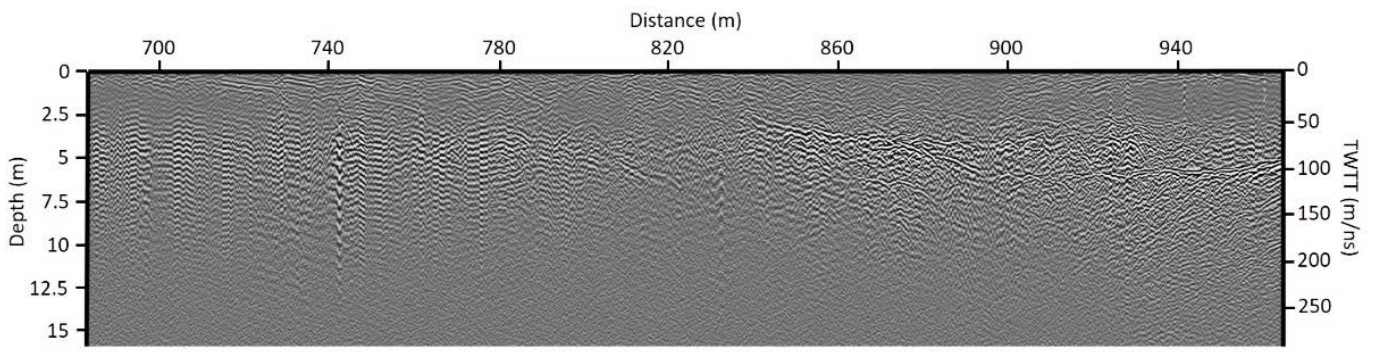


Figure A-31. Locator map for file MCM004 GPR section (Figs. A-32 to A-33) with blue lines denoting areas that contain excess or massive ice and yellow lines representing regions with minimal ice. The numbers correspond to the radar profiles in Figs. A-2 to A-5.

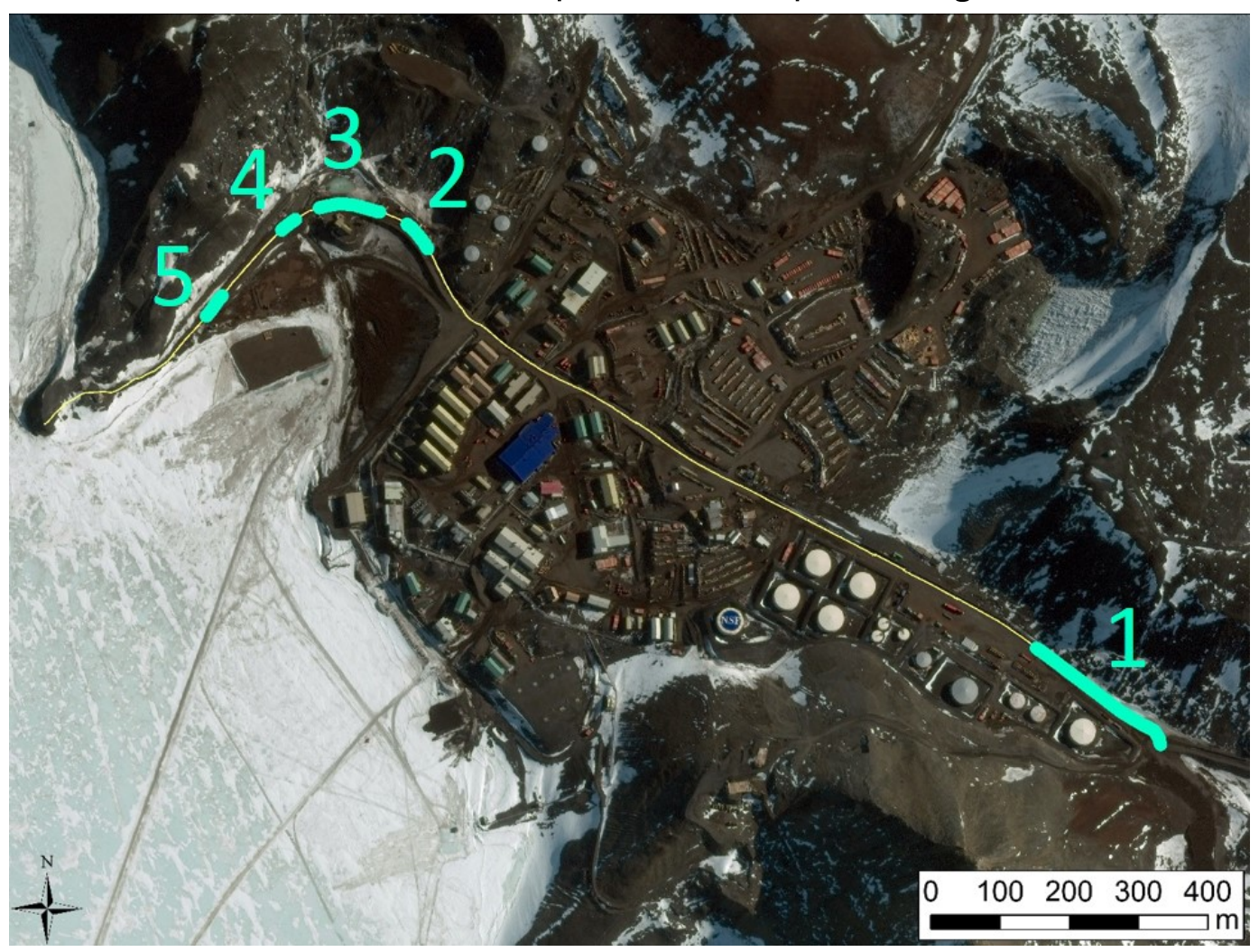

Figure A-32. GPR section 1 from Fig. A-31.

MCM_004C1C2TZDNMIGSBGS3 0-5600 scans

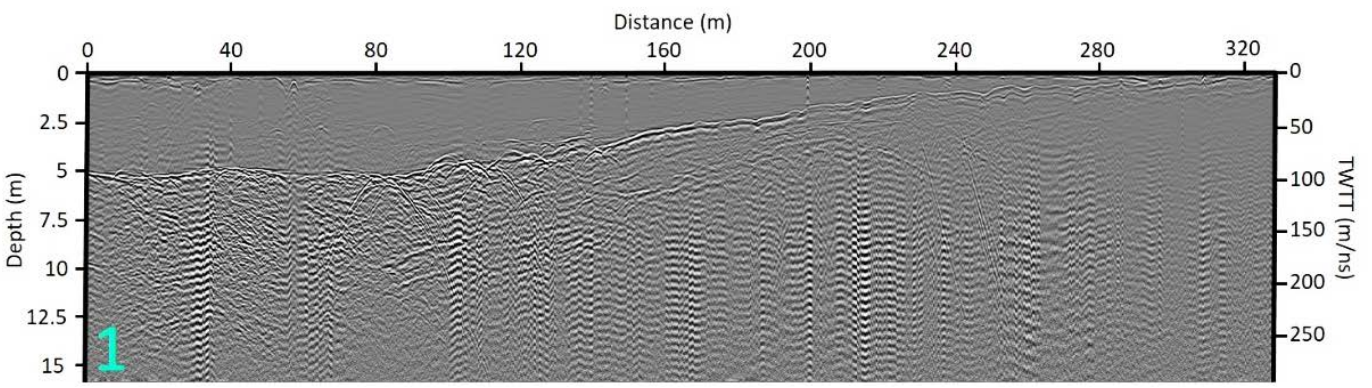

Figure A-33. GPR sections 2, 3, 4, and 5 from Fig. A-31.

MCM_004C1C2TZDNMIGSBGS3 25,900-26,800 and 27,575-29,100 and 29-745-30,175 and 32,400-33,050 scans

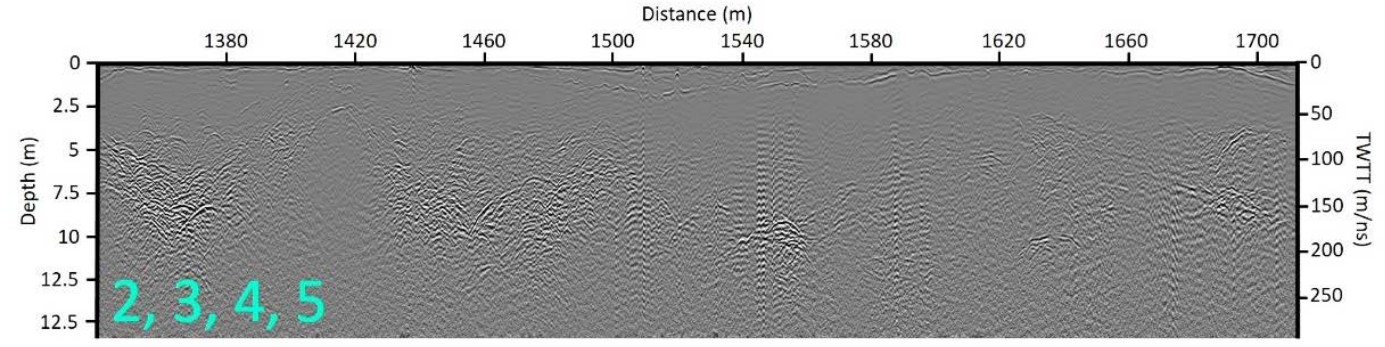


Figure A-34. Locator map for file P002 GPR sections (Fig. A-35) with blue lines denoting areas that contain excess or massive ice and yellow lines representing regions with minimal ice. The numbers correspond to the radar profiles in Fig. A-2.

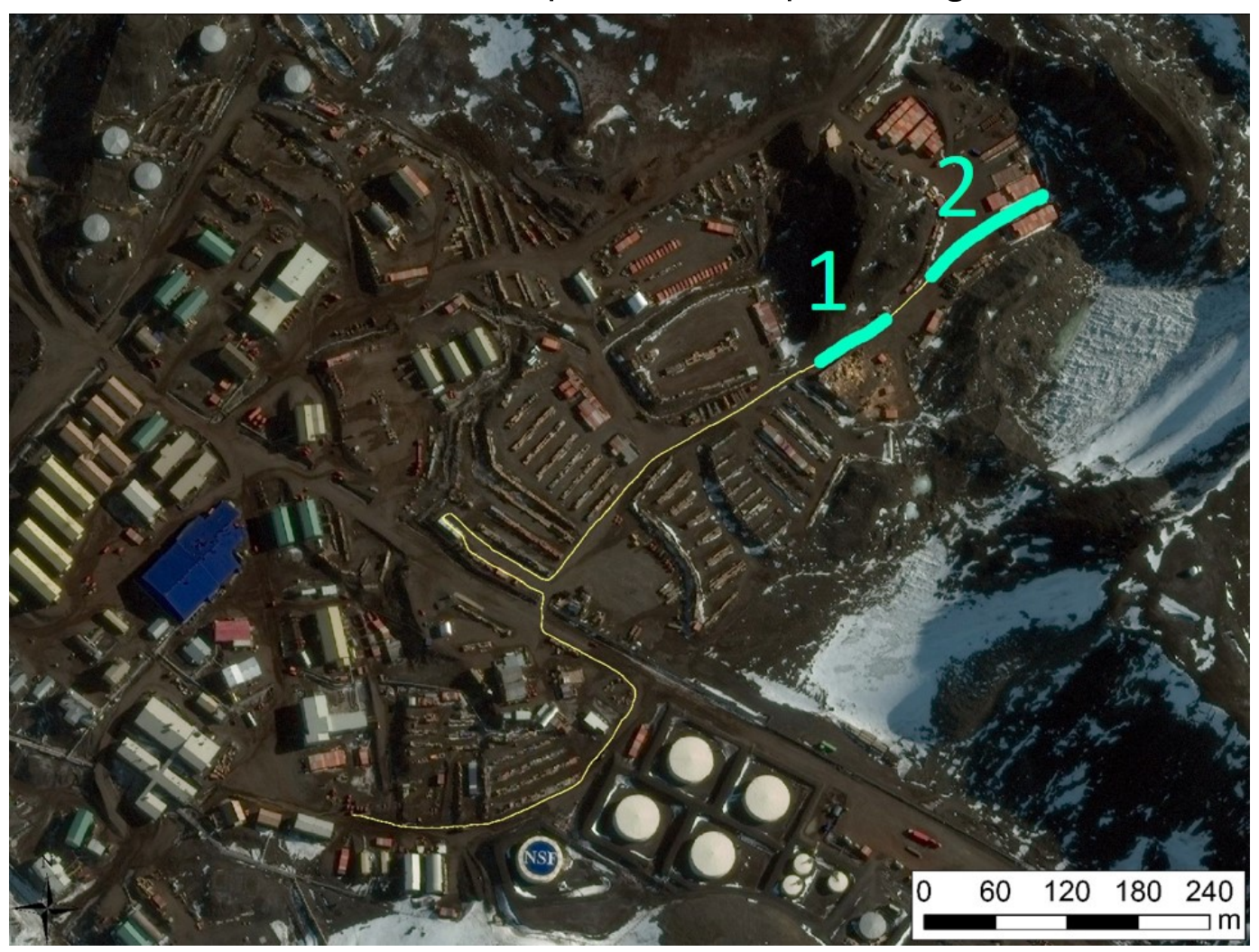

Figure A-35. GPR sections 1 and 2 from Fig. A-34.

P 002C1C2TZDNFIRBGMIGSS3 21,175-22,750 and 24,000-26,650 scans

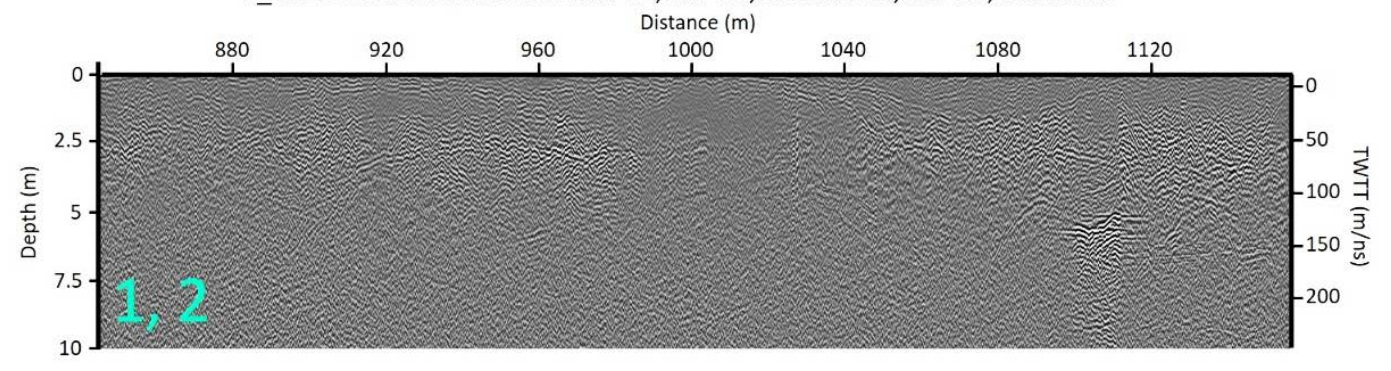


Figure A-36. Locator map for file P003 GPR sections (Figs. A-37 to A-40) with blue lines denoting areas which contain excess or massive ice and yellow lines representing regions with minimal ice. The numbers correspond to the radar profiles in Figs. A-2 to A-5.

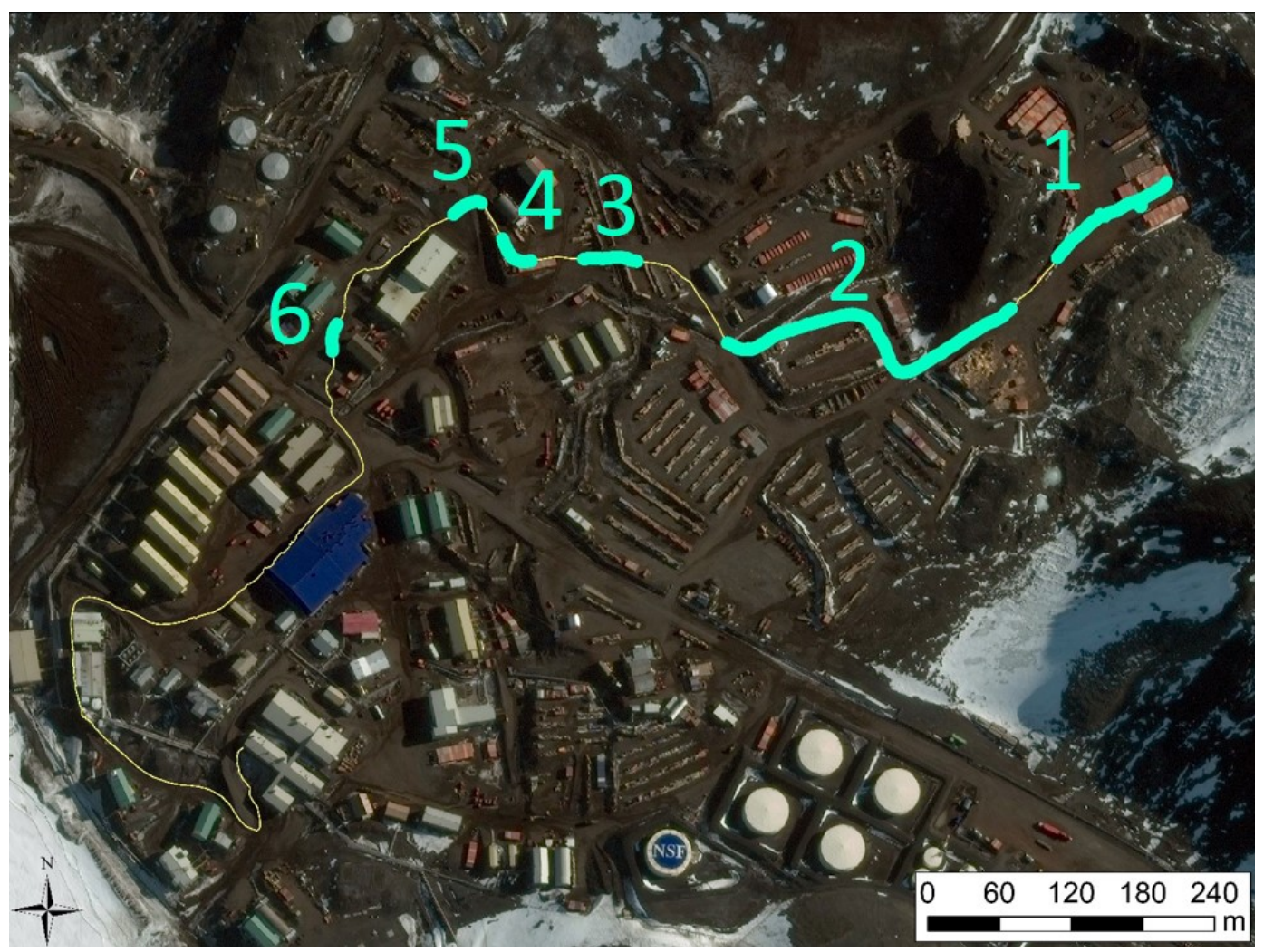

Figure A-37. GPR section 1 from Fig. A-36.

\section{P_003C1C2TZFIRBGDNMIGSS3 0-2,650 scans}

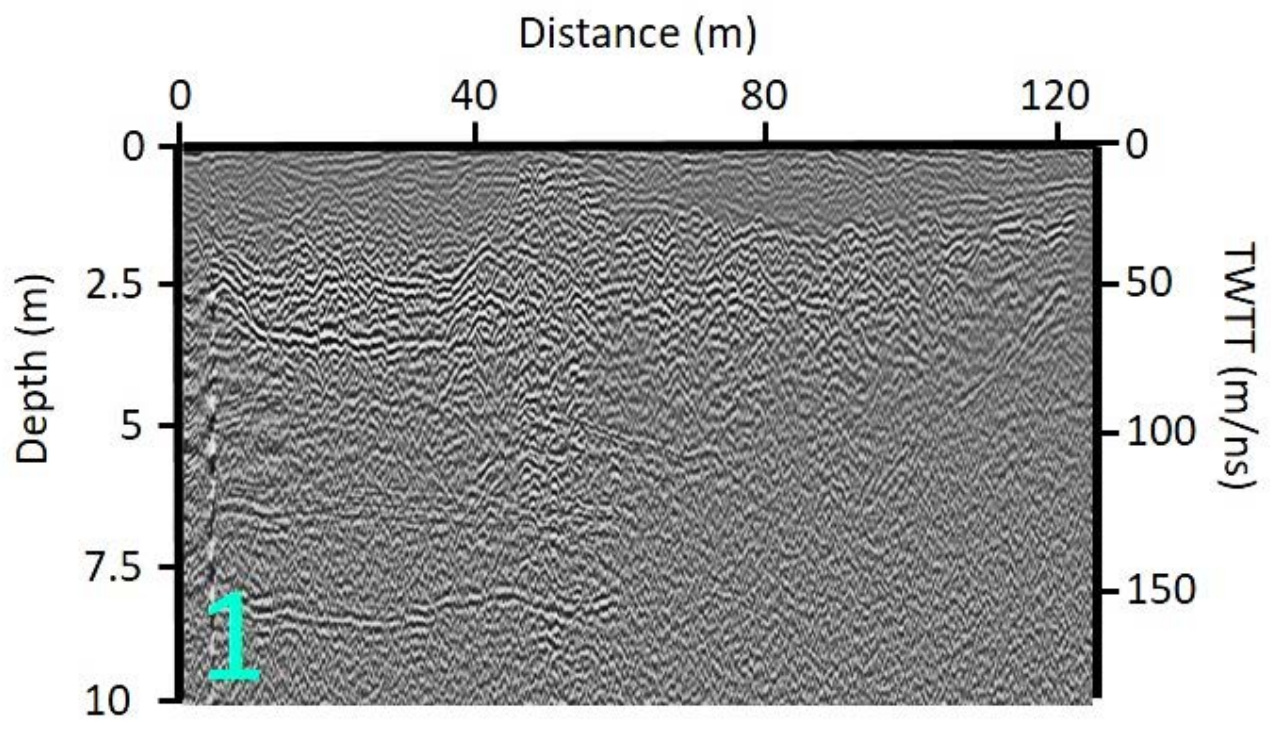


Figure A-38. GPR section 2 from Fig. A-36.

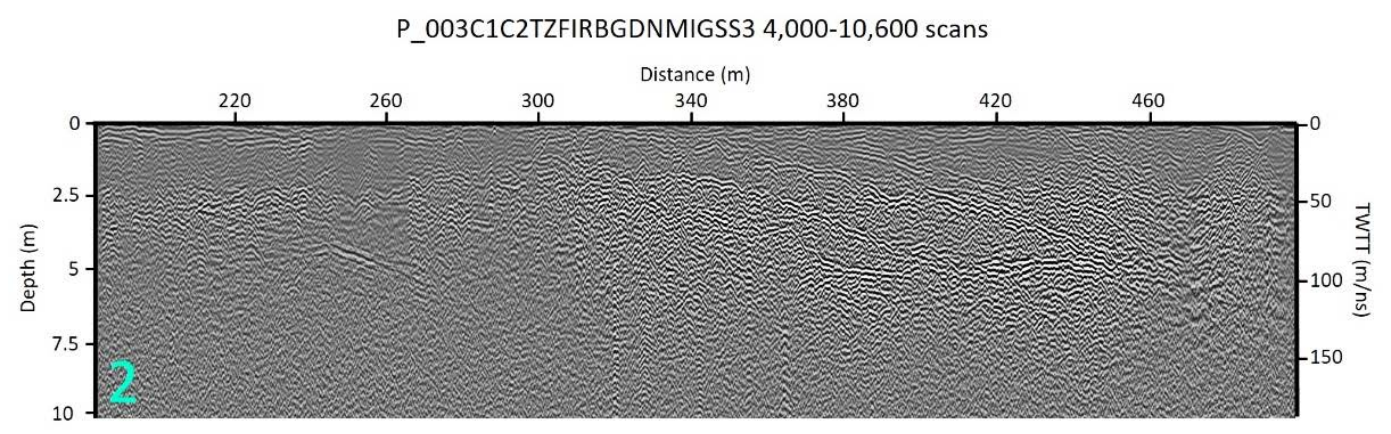

Figure A-39. GPR sections 3, 4, and 5 from Fig. A-36.

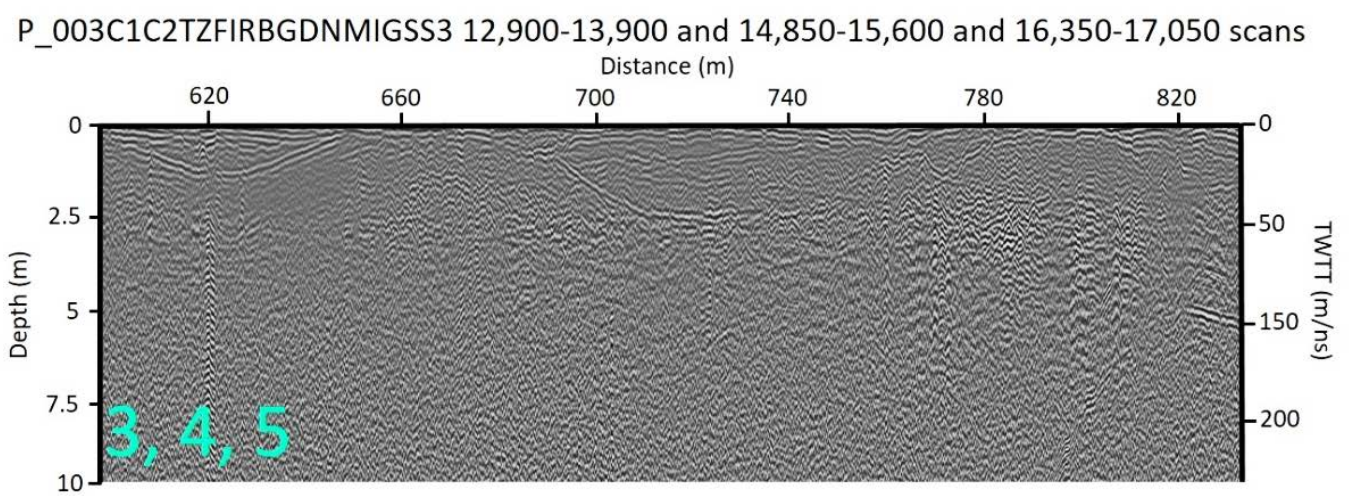

Figure A-40. GPR section 6 from Fig. A-36.

\section{P_003C1C2TZFIRBGDNMIGSS3 20,100-20,600 scans}

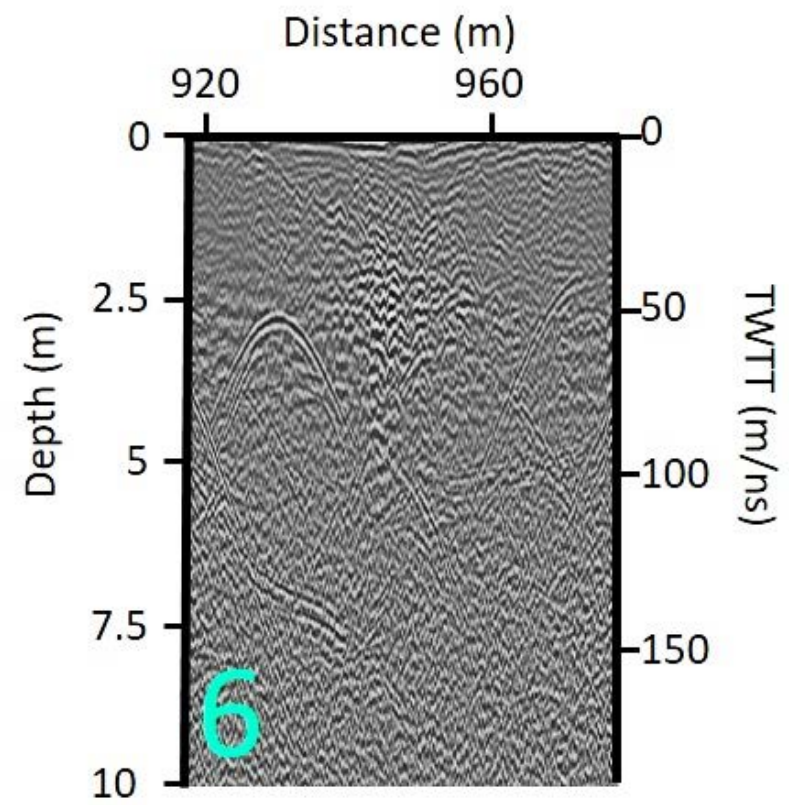




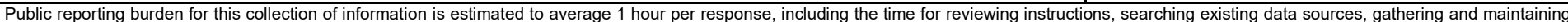

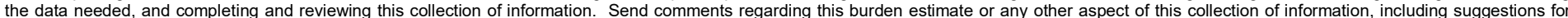

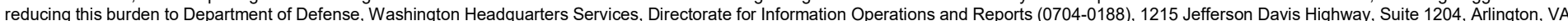

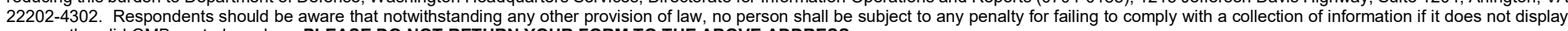
a currently valid OMB control number. PLEASE DO NOT RETURN YOUR FORM TO THE ABOVE ADDRESS.
1. REPORT DATE (DD-MM-YYYY)
2. REPORT TYPE
March 2018
Technical Report/Final

3. DATES COVERED (From - To)

\section{TITLE AND SUBTITLE}

Using Ground-Penetrating Radar to Delineate Regions of Massive Ice at

McMurdo Station, Antarctica

\section{5a. CONTRACT NUMBER}

5b. GRANT NUMBER

5c. PROGRAM ELEMENT NUMBER

\section{AUTHOR(S)}

Samantha Sinclair, Seth Campbell, Steven Arcone, and Rosa Affleck

\section{5d. PROJECT NUMBER}

5e. TASK NUMBER

EP-ANT-17-67

5f. WORK UNIT NUMBER

\section{PERFORMING ORGANIZATION NAME(S) AND ADDRESS(ES)}

8. PERFORMING ORGANIZATION REPORT
NUMBER

U.S. Army Engineer Research and Development Center (ERDC)

Cold Regions Research and Engineering Laboratory (CRREL)

ERDC/CRREL TR-18-4

72 Lyme Road

Hanover, NH 03755-1290

\section{SPONSORING / MONITORING AGENCY NAME(S) AND ADDRESS(ES)}

National Science Foundation, Office of Polar Programs

2415 Eisenhower Avenue

Alexandria, VA 22314

10. SPONSOR/MONITOR'S ACRONYM(S)

NSF

11. SPONSOR/MONITOR'S REPORT NUMBER(S)

\section{DISTRIBUTION / AVAILABILITY STATEMENT}

Approved for public release; distribution is unlimited.

\section{SUPPLEMENTARY NOTES}

Engineering for Polar Operations, Logistics, and Research (EPOLAR)

\section{ABSTRACT}

In November through December 2015, ground-penetrating-radar (GPR) data were collected at McMurdo Station, Antarctica, to better understand the near-surface geology, to find and delineate regions of excess or massive ice, and to inform future construction efforts. Of the $55 \mathrm{~km}$ of data collected, approximately $40 \%$ were analyzed and described in previous studies. In this study, we processed and analyzed the remaining data located within proposed areas for future construction. Both 400 and $200 \mathrm{MHz}$ antennas were used for data collection, with depth penetrations reaching 5 and $10 \mathrm{~m}$ for each antenna, respectively. Near-surface features detected include massive or excess ice, bedrock, and buried utilities. Ground-truth data, including soil pits and borehole logs, corroborate our interpretations. A considerable amount of nearsurface excess ice likely has anthropogenic origins from runoff refreezing in shaded areas. Our results show that the subsurface of McMurdo is characterized by a substantial amount of frozen ground that will require navigation in both the planning and construction efforts associated with rebuilding McMurdo Station.

\section{SUBJECT TERMS}

EPOLAR, Excess Ice, Frozen ground, Geographic information systems, Geology, Global Positioning System, Ground penetrating radar, Massive Ice, McMurdo Station (Antarctica), Near-Surface Geology, NSF, Permafrost

\section{SECURITY CLASSIFICATION OF:}

\section{a. REPORT}

Unclassified

b. ABSTRACT
Unclassified

\section{LIMITATION} OF ABSTRACT

\section{c. THIS PAGE}

Unclassified
18. NUMBER OF PAGES

43 19a. NAME OF RESPONSIBLE PERSON

19b. TELEPHONE NUMBER (include area code) 